\title{
INDUSTRIAL RESEARCH AND DEVELOPMENT AND REAL EXCHANGE RATE DEPRECIATION IN A SMALL OPEN ECONOMY
}

\begin{abstract}
Saleh S. Tabrizy ${ }^{* \dagger+}$
Abstract: To examine how changes in relative national prices affect innovation input, this paper studies the impact of changes in industry-specific effective real exchange rates on industrial R\&D expenditures in Korea. In particular, it explores the heterogeneous responses of industries with different export intensities. Employing dynamic panel data estimation techniques, the results suggest that among industries with medium levels of export intensity a lagged depreciation in industry-specific effective real exchange rate leads to a decline in contemporaneous industry-level R\&D expenditures. However, this adverse effect is insignificant for industries that either mostly serve the domestic markets or that are heavily engaged in foreign markets.
\end{abstract}

Keywords: R\&D; Exchange Rate; Export Intensity

JEL Classification: O32; F31

\footnotetext{
* I am grateful to Rebecca Neumann for her supervision. I am also grateful to an anonymous referee, Kundan Kishor, Suyong Song, Mohsen Bahmani-Oskooee, Avik Chakrabarti, Niloy Bose, and Ariel Weinberger for their advice. Further, I would like to thank seminar participants at University of Wisconsin - Milwaukee, the University of Oklahoma, Midwest Economics Association Conference (2014), Southern Economic Association Conference (2014), and Eastern Economic Association Conference (2016) for helpful comments. Also, the regression analyses of this paper are done using two estimation procedures, one of which is written by David Roodman, and the other one is written by Giovanni S.F. Bruno. I have had free access to these estimation procedures. For this I am grateful to the authors. I remain responsible for any shortcomings and errors.

$\dagger$ The data that support the findings of this study are openly available in the resources that I describe in the manuscript.

$\$$ The University of Oklahoma, College of Arts and Sciences, Department of Economics. Mail: 308 Cate Center Drive, CCD1, No.325, Norman, OK, 73072. Email: tabrizy@ou.edu.
} 


\section{Introduction}

A growing body of international economics literature is concerned with questions that are primarily raised in the economics of innovation. Identifying the open economy determinants of investments in research and developments (henceforth, $R \& D$ ) is among those questions. In this research, I focus on how industrial $R \& D$ expenditures in a small open economy respond to changes in relative national prices, as measured by industry-specific effective real exchange rates (henceforth, IERER).

Firms' current and future profits provide the channels for the interaction between R\&D and exchange rates. For a given industry, $R \& D$ expenditures depend on the investments in $R \& D$ equipment and the utilization cost of that equipment (e.g., the wage bill for scientists, engineers, or designers). Over time, these expenditures are expected to affect the innovative capabilities and, hence, the future profitability of the industry. In return, improvements in profit provide more resources that may be allocated to R\&D activities. Considering this interdependence, changes in relative national prices may affect R\&D expenditures through, at least, three channels. First, part of the inputs that are used for innovative activities may be imported. There may also exist a complementarity between other imported inputs and R\&D activities (e.g., Bøler, Moxnes, and Oltviet-Moe, 2015). Lastly, current and future profits that provide resources for innovative activities depend partially on export revenue. For a given industry, the ultimate effect of these offsetting forces may depend on the importance of exporting activities, the reliance on imported inputs, and the relative magnitude of pass-through elasticities.

In this study, I employ industry-level observations from a panel of manufacturing industries in the Republic of Korea. The dataset in use includes information about the IERERs and industry-level R\&D expenditures, as well as industry-level value-added, exports, and imports. It offers variations across 22 manufacturing industries over a 15-year window: from 2001 to 2015. During this period, R\&D expenditures increased significantly in Korea. In 2001, the gross domestic R\&D expenditures in Korea was $2.34 \%$ of its GDP, just slightly above the figure for all OECD countries $(2.16 \%)$. By 2015 , the gross domestic R\&D expenditures in Korea reached $4.22 \%$ of its GDP, while the same figure for all OECD 
countries remained almost steady (2.34\%). In fact, no other OECD country experienced such consistent growth in R\&D activities during this time window (OECD, 2019).

I employ a dynamic model to examine the effects of lagged changes in IERER on contemporaneous changes in industry-level R\&D. I control for lagged changes in industry-level R\&D expenditures, contemporaneous and lagged changes in other important covariates, and time-invariant unobserved industry-specific characteristics. Considering the cross-section and time-series dimensions of the above panel, I make use of the Corrected Least Square with Dummy Variables estimation procedure (Kiviet 1995, Bun and Kiviet 2003, and Bruno 2005a) to estimate the parameters of interest. Compared to conventional estimation procedures, Judson and Owen (1999), Bruno (2005b), and Buddelmeyer et al. (2008) suggest that the above procedure provides better estimation for key parameters in dynamic panel models with relatively small cross-section and time-series dimensions.

The results reveal that among industries with medium levels of export intensity a lagged depreciation in IERER (i.e., increase in price competitiveness) leads to a decline in contemporaneous industry-level R\&D expenditures. Among industries with very low or very high export intensities, however, I find no significant effects from lagged depreciation. This pattern may be the result of two factors. First, compared to industries on the tails, industries that are at the middle of export intensity distribution are likely to have relatively low pass-through elasticities (Garetto, 2016). Second, despite their differences in exports intensity, evidence from input-output tables suggest that the reliance of Korean industries with medium levels of export intensity on imported intermediate inputs is similar to the reliance of other industries on those inputs. Given the complementarity between international sourcing and R\&D activities (Bøler et al. 2015), an increase in the relative price of imported inputs as a result of real depreciation may adversely affect $R \& D$ investments. ${ }^{1}$ The reliance on imported inputs being similar among all industries, this adverse effect may in particular be significant among industries that have relatively low pass-through elasticities, which include industries that are at the middle of the export

\footnotetext{
${ }^{1}$ Chen (2017) offers a detailed description of how this complementarity may govern the relationship between exchange rate and R\&D expenditures.
} 
intensity distribution. This finding improves our understanding of how industrial R\&D expenditures may react to changes in relative national prices in a small open economy.

Previous empirical findings are summarized in Section 2. The data in use are fully described in Section 3. The empirical analyses are discussed in Section 4. Section 5 concludes.

\section{Background}

This study contributes to a growing body of empirical research on the linkages between innovation and selected open economy variables. While others examine the effects of greater access to foreign markets (e.g., Baldwin and Gu, 2004; Lileeva and Trefler, 2010; Damijan, Kostevc, and Polanec, 2010; Bustos, 2011) or import competition (e.g., Scherer and Huh, 1992; Teshima, 2008; Bloom, Draca, and Van Reenen, 2016; Autor et al., 2017), this paper explores the effect of changes in relative national prices. Within this line of literature, the existing empirical studies are of two types. Some of them examine the effect of exchange rate uncertainty or volatility on R\&D expenditures. Others examine the direction of changes in R\&D expenditures following exchange rate swings. Empirical evidence showing an adverse effect of exchange rate uncertainty or volatility on $R \& D$ expenditures seem to be conclusive (e.g., Becker and Hall; 2009, Mahagaonkar, Schweickert, and Chavali, 2009; Ito and Haneda, 2017). However, evidence on the direction of changes in R\&D expenditures in response to changes in relative national prices remain inconclusive. In what follows, I review the previous research in this line of literature. Table 1 summarizes the key findings.

There are two early studies that explore firm level data from the US. Zietz and Fayissa (1994) suggest that changes in $\mathrm{R} \& \mathrm{D}$ expenditures in response to exchange rate appreciation are conditional upon firms' innovation efforts. Using the observations from a panel of manufacturing firms in the US, they provide some evidence suggesting that firms in $R \& D$-intensive industries increase their $R \& D$ expenditures following the increase in import competition caused by exchange rate appreciation. Yet, they do not find any significant responses among firms that are not involved in R\&D-intensive industries. Funk (2003) suggests that changes in R\&D expenditures in response to exchange rate swings may depend on firms' export status. Exploring another panel of manufacturing firms in the US, he finds that exchange 
rate appreciation negatively affects the $R \& D$ expenditures of purely domestic firms, but it has no significant effects on the R\&D expenditures of exporters. He also finds that exporters increase their R\&D expenditures following an increase in their competitive advantage caused by exchange rate depreciation.

More recently, Kaiser et al. (2017) examine a firm-level panel data from Switzerland. They propose that changes in $R \& D$ expenditures in response to exchange rate swings are conditional upon firms' exposure to international markets, measured by firms' exports, imported intermediate inputs, and import competition. They find that firms with average net exposure to international markets reduce their $\mathrm{R} \& \mathrm{D}$ expenditures following an appreciation in real exchange rate. This is similar to what Becker and Pain (2008) report for the UK. Exploring aggregate variations in $R \& D$, they suggest that exchange rate appreciation is among the key forces that led to a decline in R\&D expenditures in the UK during 1990s.

Given their initial findings, Kaiser et al. (2017) explore some heterogeneities in responses. They argue that the above effect could vary, depending on firms' profitability or their size. They find that firms with very limited financial means lower their R\&D expenditures following an appreciation in real exchange rate. However, firms with considerable financial means increase their R\&D expenditures following a similar shock to exchange rate. They also find that firms that are R\&D-intensive, large, and internationally exposed reduce their R\&D expenditures following an appreciation in real exchange rate. In contrast, firms that are R\&D-intensive, small, and are not internationally exposed increase their R\&D expenditures following a similar shock to exchange rate.

The above findings are mostly about real appreciation. When it comes to real exchange rate depreciation, Funk (2003) and Kaiser et al. (2017) suggest that an increase in price competitiveness may provide some firms with incentive to spend more on $\mathrm{R} \& \mathrm{D}$. This is evident, for example, among exporters (Funk, 2003). Alfaro et al. (2018) also find a similar pattern among firms in export-oriented emerging economies in Asia. Exploring a large firm-level dataset, they find that in these countries real depreciation may increase the probability that firms engage in R\&D activities. In contrast, Chen (2017) offers some evidence from a large panel of countries that suggest that undervaluing the exchange rate has an adverse effect on R\&D expenditures. This is, in particular, evident among developed countries. Alfaro et al. 
(2018) also find that, unlike emerging Asian economies, real depreciation has an adverse effect on R\&D expenditure in other emerging economies, including countries in Latin America and Eastern Europe. ${ }^{2}$

Against the backdrop of previous studies, this paper explores how an increase in industry-level price competitiveness (i.e., IERER depreciation) may affect industry-level R\&D expenditures in a small open economy. Rather than an aggregate exchange rate index, I employ an industry-specific exchange rate measure, which offers a better measurement for industry-level relative national prices. Also, given the importance of exporting activities, as highlighted in Funk (2003), Kaiser et al. (2017), and Alfaro et al. (2018), I examine the heterogenous responses among industries with varying export intensities.

I employ industry-level data from Korea, which is widely considered as a major contributor to manufacturing R\&D in the world. The most recent OECD's Science, Technology, and Industry Scoreboard (OECD, 2017b) suggests that the total R\&D performance in Korea is about $4.22 \%$ of its GDP in 2015. ${ }^{3}$ This implies that, compared to the rest of the world, this country has one of the highest ratios of R\&D expenditures to GDP. In particular, Korea is a leading country in information and communication technology as well as artificial intelligence. ${ }^{4}$ Korea is also a major exporter. In 2017, it was ranked as the $6^{\text {th }}$ leading exporter in merchandise trade and as the $17^{\text {th }}$ leading exporter in commercial services. ${ }^{5}$ The majority of its merchandise exports, $89.7 \%$ in 2017, are also made up of manufacturing products (WTO, 2019). That is why sample evidence from manufacturing industries in Korea are quite useful in exploring the effects of changes in relative national prices on $R \& D$ expenditures.

The findings are twofold. For industries that are at the middle of export intensity distribution, I find that a lagged depreciation in IERER leads to a decline in contemporaneous industry-level R\&D expenditures. This adverse effect is consistent with the findings by Alfaro et al. (2018) for firms in Latin America and Eastern Europe as well as the findings by Chen (2017) for developed countries. That said,

\footnotetext{
${ }^{2}$ It is worth noting that Alfaro et al. (2018) find no significant relationships between exchange rate depreciation and R\&D expenditures in industrialized countries.

${ }^{3}$ In comparison, this ratio is about $3.29 \%$ and $2.07 \%$ for Japan and China, respectively.

${ }^{4}$ Depending on their class, between $10 \%$ and $46 \%$ of recent patenting activities in information and communication technology and about $17.5 \%$ of recent patenting activities in artificial intelligence are originated in Korea (OECD, 2017b).

${ }^{5}$ Korea's rank is higher when intra-EU trade is excluded. In that case, it is ranked as the $5^{\text {th }}$ leading exporter in merchandise trade and as the $9^{\text {th }}$ leading exporter in commercial services in 2017 (WTO, 2019).
} 
for industries that are at the tails of export intensity distribution (i.e., industries that mostly serve the domestic market and industries that are heavily engaged in foreign markets), I find that a lagged deprecation has no significant effects on contemporaneous R\&D expenditures. These findings highlight the importance of industry-level heterogeneities in exporting activities. While on average there are no significant relationships between changes in industry-level relative national prices and R\&D expenditures in Korea, exploring industry-level heterogeneities suggests that $R \& D$ expenditures of industries with medium levels of export intensity may be adversely affected by real depreciation.

\section{Data}

In the regression analyses below, I make use of five data sources. The annual industry-level R\&D expenditures come from the OECD's Business Enterprise R\&D Expenditure by Industry (OECD, 2017a). I use the ISIC Rev. 3.1 version of this dataset to collect the annual R\&D information from 2001 to 2014. Where matching is possible, I also use the ISIC Rev. 4 version of this dataset to collect the information for 2015. For most industries, therefore, I am able to explore the annual industry-level R\&D expenditures from 2001 to 2015. The annual IERER data comes from a new RIETI dataset, called: Industry-Specific Nominal and Real Effective Exchange Rates of 25 Countries Worldwide (RIETI, 2018). These industrylevel exchange rate measures are available beginning in 2001 in daily and monthly increments. Exchange rates in this dataset are measured in both nominal and real terms. For a given industry, I take the mean of the monthly real exchange rates in order to measure the annual rates. I also employ many control covariates. The annual industry-specific value-added measure comes from the OECD's STAN Industrial Analysis (OECD, 2017c). The annual industry-specific exports and imports come from the UN Comtrade (WITS, 2018). Lastly, the annual aggregate nominal exchange rate and interest rate come from IMF's International Financial Statistics (IMF, 2018).

The sample in use consists of 22 industries in Korea. Table A.1 in the appendix provides a list of these industries along with their ISIC Rev. 3 codes. On average, these industries contribute to more than 98\% of manufacturing R\&D in Korea. As shown in Figure 1, the Electrical Equipment industry has the greatest share of the entire manufacturing $R \& D$ expenditures in this sample (slightly more than 55\%). 
Also, the Motor Vehicles, Trailers, and Semi-trailers industry has a large share (slightly less than 15\%). Further, the Machinery and Equipment N.E.C., Chemical and Chemical Products (Less Pharmaceuticals), Computer, Electronic, and Optical Products, and Pharmaceuticals each contributes less than 10\% but greater than 2\%. Lastly, the Rubber and Plastic Products, Basic Metals: Iron and Steel, Ships and Boats, and Food Products and Beverages each contributes less than 2\% but greater than $1 \%$. Altogether, the remaining 12 industries contribute to only about $4.25 \%$ of manufacturing R\&D in Korea.

I employ the IERER indices to introduce an empirically relevant source of relative price variations to the regression functions. This measure is a function of aggregate nominal exchange rates, industry-specific producer price indexes, and industry-specific trade weights. In what follows, I briefly explain how IERERs are measured. ${ }^{6}$ To begin with, let $N E R_{f, t}$ be the nominal exchange rate at time $t$, defined as the price of foreign currency measured in Korean won. Then, consider industry $i$ in Korea $(h)$ and the same industry in a foreign country $(f)$. Let $P_{i, t}{ }^{(h)}$ and $P_{i, t}^{(t)}$ be the price indices for that industry in Korea and the foreign country, respectively. Given these variables, one may define an industry-specific bilateral real exchange rate measure $\left(B R E R_{i, t}{ }^{\left({ }^{f}\right)}\right)$ in the following way:

$$
\operatorname{BRER}_{i, t}^{(f)}=\frac{\left(\frac{1}{N E R_{f, t}}\right) \times P_{i, t}^{(h)}}{P_{i, t}^{(f)}}
$$

For a given industry and at a given time, the above measure is the ratio of Korean price index, measured in foreign currency, over foreign price index, which is again measured in foreign currency. Keeping the nominal exchange rate and foreign price index fixed, an increase in Korean prices (i.e., lower price competitiveness) would imply an appreciation in bilateral real exchange rate, while a decline in Korean prices (i.e., greater price competitiveness) would imply a depreciation in bilateral real exchange rate. Also, keeping the Korean and foreign prices fixed, a decline in nominal exchange rate (i.e., appreciation of Korean won) would imply an appreciation in bilateral real exchange rate, while an increase in nominal exchange rate (i.e., depreciation of Korean won) would imply a depreciation in bilateral real exchange

\footnotetext{
${ }^{6}$ Refer to Sato et al. (2015) for more details about the definition and computation of this measure.
} 
rate. Thus, greater industry-specific price competitiveness or nominal exchange rate depreciation may both lead to a depreciation in industry-specific bilateral real exchange rate. In practice, however, Korea has multiple trade partners. This implies that, for a given industry and at a given time, there are multiple bilateral real exchange rates. Plus, in such industry, the amount of exports to different trade partners may vary. It is, therefore, vital to employ the share of exports to each destination $\left(\alpha_{i, t}^{(f)}\right)$ in order to construct an effective real exchange rate measure. Given the above components, the IERER for industry $i$ at time $t$ is defined as:

$$
\operatorname{IERER}_{i, t}=\prod_{f=1}^{n}\left(B R E R_{i, t}^{(f)}\right)^{\alpha_{i, t}^{(f)}}
$$

An increase in this measure is considered an appreciation of the IERER measure, which implies lower price competitiveness for a given industry in Korea. A decline is considered a depreciation, which implies greater price competitiveness.

Two points should be highlighted about this variable. First, RIETI (2018) reports this measure on daily and monthly bases. However, since I only have access to annual variations in industry-level R\&D expenditures, I employ the reported monthly variations to compute the average annual IERER. Second, I employ an index for the variations in IERER. For a given industry, this index normalizes IERER value in 2001 and puts it equal to 100. Adding an aggregate manufacturing ERER index, Figure 2 plots the variations in the IERERs. This figure illustrates how the measure in use may vary across different industries, and how it may differ from an aggregate measure.

There is also a data limitation that should be highlighted. As indicated above, I observe the annual variations in $R \& D$ expenditures for 22 industries. However, the annual variations in IERER measures are not available for all of those industrial categories. For example, while OECD (2017a) reports the annual R\&D expenditures for Food Products and Beverages industry and Tobacco Products industry separately, RIETI (2018) only reports the IERER measure for Food, Beverages, and Tobacco industry (Sato et al. 2015, P. 4). In order to make sure that a large and representative sample is available, I use the R\&D data as the main dataset and match the IERER measures accordingly. Table 2 offers detailed information about 
this matching procedure. Also, Figure A.1 in the appendix includes time series plots of variations in $\log$ IERERs and log real R\&D expenditures for all industries.

\section{Empirical Analyses}

The underlying empirical question in this study is the following: does an increase in industry-level price competitiveness, as measured by the IERER measures, lead to any significant changes in industry-level $\mathrm{R} \& \mathrm{D}$ expenditures?

To address this question, I rely on dynamic panel data estimations and employ the sample information described in Section 3. I introduce the estimation approach in Section 4.1. I report the baseline regression in Section 4.2. I modify the baseline regression to estimate the effects of real depreciation versus appreciation on R\&D expenditures in Section 4.3. I further modify the baseline regression to explore the heterogeneities in responses in Section 4.4. I report the estimation and robustness results in Section 4.5. Lastly, I discuss some of the factors that could explain the key findings in Section 4.6.

\subsection{Estimation Approach}

I use a dynamic panel model to address the underlying question of this paper. In this model, contemporaneous changes in industry-level $\mathrm{R} \& \mathrm{D}$ expenditures are determined by lagged changes in industry-level R\&D expenditures, lagged changes in IERER measures, and contemporaneous and lagged changes in control covariates, including industry-level value-added, exports, imports, and an aggregate measure of interest rate. I also control for few binary covariates, including time dummies (in all estimations), exchange rate depreciation dummy (used along with key interaction terms introduced in Sections 4.3 and 4.4), and financial crisis dummy (in robustness tests). Lastly, I include a fixed-effect parameter, controlling for time-invariant unobserved industry-specific characteristics.

It is common to employ dynamic models to examine the variations in $R \& D$ expenditures. This modeling approach stems from the persistent pattern that is often observed in innovative activities. Considering innovation output, for example, Raymond et al. (2010) suggest that the probability of innovating and the intensity of innovation output among high-tech industries are persistent. Antonelli, 
Crespi, and Scellato (2012) also find a persistence in R\&D-based innovative efforts, in particular when there are significant entry barriers (e.g., sunk costs) for R\&D activities. Further, considering innovation input, Falk (2006) documents a persistent pattern in business-sectors R\&D expenditures within a large panel of OECD countries. Woerter (2014) also reports that R\&D expenditures tend to be persistent in markets with few principal competitors. As competition increases, however, he finds that the R\&D persistence declines. Given these findings, it is necessary to control for lagged variations in R\&D activities. Otherwise, the results may suffer from omitted variable bias.

Since sample size is relatively small, I estimate the parameters of this model using a Corrected Least Squares with Dummy Variable estimator (henceforth, LSDVC). This estimation procedure was first proposed by Kiviet (1995). Estimating the parameters of a dynamic panel model with small time dimension, he explores the analytic small sample bias when a Least Square with Dummy Variable estimator is employed. Correcting for the bias, he shows that the adjusted estimator could perform quite efficiently. This bias correction, as Bun and Kiviet (2003) suggest, could in practice be based on simple bias approximation formula, which makes the LSDVC estimation procedure quite straightforward. Against this backdrop, Judson and Owen (1999) examine balanced datasets where time dimension is less than 10 , equal to 10 , equal to 20 , or equal to 30 , and they show that in all of these cases the LSDVC estimator performs better than Generalized Method of Moment estimators (henceforth, GMM). However, their findings require balanced datasets. To apply the LSDVC estimation procedure in unbalanced datasets, Bruno (2005a) proposes a set of bias approximations that extend the approximations done in Bun and Kiviet (2003). Based on these bias approximations, Bruno (2005b) examines unbalanced datasets where time dimension is on average equal to 20 or 40. Similarly to Judson and Owen (1999), he finds that the LSDVC procedure performs better than GMM in estimating the autoregressive and slope parameters. Buddelmeyer et al. (2008) also show that the LSDVC procedure could perform well when it comes to estimating the fixed effect parameter.

As indicated in Section 3, I employ an unbalanced dataset, including 22 industries over 15 years. The size and structure of this dataset are quite similar to the size and structure of datasets that are 
examined in above-mentioned studies. ${ }^{7}$ Because of these similarities, I estimate the parameters of interest following the LSDVC estimation procedure. Given the findings in Bruno (2005a and 2005b) and

Buddelmeyer et al. (2008), I expect that the resulting estimations are efficient and unbiased.

\subsection{Baseline Regression}

The baseline regression function is as follows:

$$
\begin{aligned}
\Delta R D_{i, t}= & \gamma \Delta R D_{i, t-1}+\alpha \Delta I E R E R_{i, t-1}+\Delta X_{i, t}^{\prime} \beta_{1}+\Delta X_{i, t-1}^{\prime} \beta_{2} \\
& +\beta_{3} t+T^{\prime} \beta_{4}+\eta_{i}+\varepsilon_{i, t}
\end{aligned}
$$

where $\Delta R D_{i, t}$ is the contemporaneous changes in industry $i$ 's $\mathrm{R} \& \mathrm{D}$ expenditures, $\Delta R D_{i, t-1}$ is the lagged changes in industry $i$ 's R\&D expenditures, and $\triangle I E R E R_{i, t-1}$ is the lagged changes in industry $i$ 's IERER. I include vectors of contemporaneous and lagged changes in industry-specific control covariates $\left(\Delta X_{i, t}\right.$ and $\left.\Delta X_{i, t-1}\right)$ in order to account for other factors affecting $\Delta R D_{i, t}$ I control for the time trend in the changes in R\&D expenditures using the time trend variable, $t$. I also include a vector of time dummies, $T$, to control for year-specific common shocks to the changes in R\&D expenditures. Further, $\eta_{i}$ is the fixed-effect parameter, controlling for time-invariant unobserved industry-specific characteristics. Lastly, $\varepsilon_{i, t}$ is an i.i.d. error term. For a given industry and over the entire time series, I assume that $\eta_{i}$ and $\varepsilon_{i, t}$ are independent from each other.

In Equation 3, industry-level R\&D expenditures and control covariates, including industry-level value-added $(Y)$, exports $(X)$, and imports $(M)$, are measured in Korean won. They are all deflated using an aggregate producer price index. ${ }^{8} \mathrm{I}$ also include an aggregate measure of interest rate $(r)$ into the vector of control covariates. Before taking their first-difference, the R\&D expenditures, IERER measures, and control covariates are put in natural logarithm. ${ }^{9}$

\footnotetext{
${ }^{7}$ For example, one of the simulated unbalanced datasets in Bruno (2005b, pp. 481-485) consists of 20 cross-section-units and on average 20 time-units, which is very similar to the panel in use in this study.

${ }^{8}$ WITS (2018) report the export and import data in US dollars. I transform them to Korean won using an aggregate measure of the exchange rate as provided by IMF (2018). The producer price index also comes from IMF (2018). The index is set equal to 100 for the year 2001 .

${ }^{9}$ The only exception is the measure of interest rate, which is not put in log.
} 
Industry-level R\&D, IERER, and covariates such as value-added, exports, and imports are quite persistent. To avoid spurious results, I employ their first-difference variations (e.g., $\Delta R D$ ) rather than their level variations (e.g., $R D$ ). Table 3 shows the results of the unit root test developed by Im, Pesaran, and Shin (2003), suggesting that the first-differences are likely to be stationary. Exploring the variations in first-differences, a parameter like $\alpha$ captures the effect of an increase or a decline in lagged changes in IERER on contemporaneous changes in R\&D.

In Equation 3, I employ the lagged changes in IERER measures in order to make sure that changes in IERER are exogenous to changes in industry-level R\&D expenditures. ${ }^{10}$ Under this timing, a shock to $\varepsilon_{i, t}$ affects $\Delta R D_{i, t}$, but it has no effects on $\triangle I E R E R_{i, t-1 .}$. Plus, this timing allows for the possibility that firms in a given industry react to changes in relative national prices with a lag. Allowing for this delay is, in particular, important for R\&D expenditures, as they depend on investments in $R \& D$ equipment as well as utilization or adjustment costs that typically react with delays. I also include a vector of lagged changes in control covariates, including lagged changes in value-added, exports, and imports, to fully isolate the effects of lagged changes in IERER on contemporaneous changes in R\&D.

\subsection{Real Exchange Rate Depreciation}

I introduce an interaction term to set apart the effects of increase in price competitiveness, as measured by IERER depreciation, on R\&D expenditures. The modified regression function is as follows:

$$
\begin{aligned}
\Delta R D_{i, t}= & \gamma \Delta R D_{i, t-1}+\alpha_{1} \Delta I E R E R_{i, t-1}+\alpha_{2} \operatorname{Dep}_{i, t-1} \times \Delta I E R E R_{i, t-1} \\
& +\Delta X_{i, t}{ }^{\prime} \beta_{1}+\Delta X_{i, t-1}{ }^{\prime} \beta_{2}+\beta_{3} t+T^{\prime} \beta_{4}+\beta_{5} \operatorname{Dep}_{i, t-1}+\eta_{i}+\varepsilon_{i, t}
\end{aligned}
$$

where $D e p_{i, t-1}$ is a binary variable that is set equal to one when $\triangle I E R E R_{i, t-I}$ is less than zero. It is set equal to zero, otherwise. The remainder are the same variables that are used in baseline regression (Equation 3). The only difference is that, in the above regression function, I add a separate control for the time-variant binary variable that is included in the interaction term $\left(\right.$ Dep $\left._{i, t-1}\right)$.

\footnotetext{
${ }^{10}$ Chen (2017) also employs a lagged measure of currency undervaluation in order to capture the effects of undervaluing national currencies on changes in R\&D expenditures.
} 
As given by Equations 1 and 2, a lagged decline in IERER (i.e., $\triangle I E R E R_{i, t-1}<0$ ) is considered a lagged depreciation. Using the interaction term, the effect of a lagged depreciation (i.e., $D e p_{i, t-1}=1$ ) on contemporaneous changes in R\&D expenditures is captured by the sum of $\alpha_{1}$ and $\alpha_{2}$ parameters, while the effect of a lagged appreciation (i.e., $D e p_{i, t-1}=0$ ) is captured only by $\alpha_{1}$. I employ the LSDVC estimation procedure to estimate the parameters of interest in Equation 4 and test for the following hypotheses: 1.) $H_{0}: \alpha_{1}=0$, and 2.) $H_{0}: \alpha_{1}+\alpha_{2}=0$. Rejecting the first null hypothesis provides evidence for the effect of a lagged appreciation on contemporaneous changes in R\&D expenditures. Rejecting the second null hypothesis provides evidence for the effect of a lagged depreciation.

\subsection{Industry Heterogeneities}

I add another interaction term to examine whether IERER depreciations have different effects on R\&D expenditures in different industries with varying export intensities. Previous empirical findings show the importance of exporting activities in governing the relationship between exchange rate and $R \& D$ expenditures. As discussed in Section 2, Kaiser et al. (2017) suggest that, along with other covariates

(mainly, access to financial resources and the intensity of innovative activities), international exposure of firms may be a significant determinant of the effect of exchange rate swings on $R \& D$. This is also highlighted by Funk (2003) and, more recently, Alfaro et al. (2018). The intensity of exporting activities, as briefly discussed in Section 1, may have implications for engagement in strategic pricing and, hence, pass-through elasticities. Export-intensive industries are likely to offer competitive prices abroad. Thus, they are less likely to engage in strategic international pricing. Also, industries that mostly serve the domestic markets do not have enough profit margins to engage in strategic international pricing. Compared to these industries, however, Garetto (2016) suggests that industries that are at the middle of export intensity distribution are more likely to engage in strategic pricing, exhibiting low pass-through. With all else held constant (including the reliance on imported inputs), this pass-through behavior may provide less incentives for R\&D activities following real exchange rate depreciation. Engaging in strategic pricing, industries at the middle of export intensity distribution are less likely to adjust their prices (in domestic currency) in response to real exchange rate depreciation even though the cost of 
imported inputs increases. That may have negative effects on their profit margins, which in return may provide less incentives for $R \& D$ activities.

I employ the regression function below to explore the heterogeneities in industry responses:

$$
\begin{aligned}
\Delta R D_{i, t}= & \gamma \Delta R D_{i, t-1}+\alpha_{1} \Delta I E R E R_{i, t-1}+\alpha_{2} I_{i n d} \times \Delta I E R E R_{i, t-1} \\
& +\alpha_{3} \operatorname{Dep}_{i, t-1} \times \Delta I E R E R_{i, t-1}+\alpha_{4} I_{i n d} \times \operatorname{Dep}_{i, t-1} \times \Delta I E R E R_{i, t-1} \\
& +\Delta X_{i, t}^{\prime} \beta_{1}+\Delta X_{i, t-1}{ }^{\prime} \beta_{2}+\beta_{3} t+T^{\prime} \beta_{4}+\beta_{5} \operatorname{Dep}_{i, t-1}+\eta_{i}+\varepsilon_{i, t}
\end{aligned}
$$

where $I n d_{i}$ is a time-invariant binary variable that is constructed given the average export intensity for industry $i$. The remainder are the same variables that are used in Equations 3 and 4 . Since $I n d_{i}$ is timeinvariant, I do not include any separate controls for this binary variable.

To construct the new binary variable $\left(I n d_{i}\right)$, I make use of an industry-specific time-invariant variable that measures the relative importance of exports for a given industry. It is defined as:

$$
\operatorname{ExpInt}_{i}=\frac{\sum_{t=1}^{t=T}\left(\operatorname{Exp}_{i, t} / Q_{i, t}\right)}{T}
$$

where $\operatorname{Exp}_{i, t}$ and $Q_{i, t}$ stand for industry $i$ 's nominal exports and output at time $t$, respectively. For a given industry, ExpInt $t_{i}$ represents the average of the export intensity ratio over the entire time-series. The resulting industry-specific measure is plotted in Figure 3. The median value for ExpInt is $_{1} 18.92 \%$. The first quartile is $11.92 \%$, and the third quartile is $40.61 \%$.

I explore industry heterogeneities under two alternative definitions for Indi. First, I focus on differences that may exist between highly export-intensive industries and industries that are not heavily involved in exporting activities. In this case, $I n d_{i}$ is equal to one if industry $i$ 's ExpInt $t_{i}$ is greater than the median value (i.e., ExpInt ${ }_{i}>0.1892$ ). It is equal to zero, otherwise. Second, I focus on the middle part of the export intensity distribution. In this case, $\operatorname{Ind}_{i}$ is equal to one if $\operatorname{ExpInt}_{i}$ is bounded by the first and third quartile values (i.e., $0.1192 \leq$ ExpInt $_{i} \leq 0.4061$ ). It is equal to zero, otherwise. In both cases, I consider four hypotheses:

1. When $\operatorname{Dep}_{i, t-1}$ and $I n d_{i}$ are both equal to zero: $H_{0}: \alpha_{1}=0$

2. When $\operatorname{Dep}_{i, t-1}$ is equal to zero, but $I n d_{i}$ is equal to one: $H_{0}: \alpha_{1}+\alpha_{2}=0$ 
3. When $\operatorname{Dep}_{i, t-1}$ is equal to one, but $I n d_{i}$ is equal to zero: $H_{0}: \alpha_{1}+\alpha_{3}=0$

4. When $\operatorname{Dep}_{i, t-1}$ and $I n d_{i}$ are both equal to one: $H_{0}: \alpha_{1}+\alpha_{2}+\alpha_{3}+\alpha_{4}=0$

To interpret the above hypotheses, consider the second definition of the binary variable Ind $_{i}$, which is equal to one for industries with medium levels of export intensity. For industries that are at the tails of the export intensity distribution (i.e., $I n d_{i}=0$ ), the effect of a lagged appreciation (i.e., $D e p_{i, t-1}=0$ ) is captured by parameter $\alpha_{1}$ (test no. 1), while for industries that are at the middle of the export intensity distribution (i.e., $I n d_{i}=1$ ), the effect of a lagged appreciation (i.e., $D e p_{i, t-1}=0$ ) is captured by the sum of $\alpha_{1}$ and $\alpha_{2}$ (test no. 2). Similarly, for industries that are at the tails of the export intensity distribution (i.e., $\operatorname{Ind} d_{i}=0$ ), the effect of a lagged depreciation (i.e., $\operatorname{Dep}_{i, t-1}=1$ ) is captured by the sum of $\alpha_{1}$ and $\alpha_{3}$ (test no. 3), while for industries that are at the middle of the export intensity distribution (i.e., Ind $_{i}=1$ ), the effect of a lagged depreciation (i.e., Dep $_{i, t-1}=1$ ) is captured by the sum of $\alpha_{1}, \alpha_{2}, \alpha_{3}$, and $\alpha_{4}$ parameters (test no. 4).

Considering the effects of IERER depreciation on industry-level R\&D, the rejection of the fourth null hypothesis while failing to reject the third null hypothesis provides evidence for the presence of industry heterogeneities. It suggests that $R \& D$ expenditures in different industries with varying export intensities may respond to increase in price competitiveness differently.

\subsection{Results}

\subsubsection{Baseline Results}

I employ the LSDVC estimation procedure to estimate the parameters in baseline regression (Equation 3).

The initial estimators for this procedure are obtained from a one-step GMM estimation (Arellano and Bond 1991, Arellano and Bover 1995, and Blundell and Bond 1998) with a robust estimator for covariance matrix. ${ }^{11}$ Given the initial estimators, the bias correction is conducted with an accuracy of approximation up to $O\left(\frac{1}{N T^{2}}\right)$, where $N$ and $T$ are the cross-section and time-series dimensions, respectively. The variance-covariance matrix is computed using 1,000 repetitions. $^{12}$

\footnotetext{
${ }^{11}$ The p-values for Arellano and Bond tests are reported in Table 4. The remaining details of initial estimations are available upon request. Also, refer to Roodman (2009) for more information about the initiating one-step GMM estimation.

${ }^{12}$ Refer to Bruno (2005b) for more details about the estimation procedure.
} 
Controlling for lagged changes in R\&D expenditures and other important covariates, the baseline results in Table 4 suggest that lagged changes in relative national prices are not among the significant determinants of contemporaneous changes in $R \& D$ expenditures. I begin by employing a relatively small vector of control covariates, including contemporaneous and lagged changes in industry-level valueadded (column I). I then add other control covariates, including contemporaneous and lagged changes in industry-level exports and imports (column II) and central bank policy rate (column III). In all regressions, I also include a time trend, a vector of time dummies, and a fixed-effect parameter. The results suggest that lagged changes in IERER have no significant effects on contemporaneous changes in R\&D. However, there is a significant negative correlation between lagged changes in R\&D expenditures and contemporaneous changes in $\mathrm{R} \& \mathrm{D}$ expenditures. This negative correlation captures an adjustment process: a lagged increase in $R \& D$ activities leads to a decline in contemporaneous $R \& D$ activities, and a lagged decline leads to an increase. It is also evident that an increase in contemporaneous value-added is correlated with an increase in R\&D expenditures. An increase in contemporaneous exports is also correlated with an increase in $R \& D$ expenditures, but an increase in lagged exports leads to a decline in $\mathrm{R} \& \mathrm{D}$ expenditures. That said, the variations in contemporaneous and lagged changes in imports and interest rate are not significantly correlated with contemporaneous changes in R\&D expenditures. ${ }^{13}$

Taken together, the results in Table 4 suggest that previous industry-level R\&D activities are important determinants of contemporaneous R\&D activities. As expected, the growth rates of production and exports ( $\Delta Y$ and $\Delta X$, respectively) may also predict the growth rate of $\mathrm{R} \& \mathrm{D}$ expenditures. However, I do not find enough evidence suggesting that the overall changes in relative national prices, measured by

\footnotetext{
${ }^{13}$ I make use of 249 observations in this baseline regression and almost all other regressions that follow. As indicated in Section 3 , the sample in use includes 22 industries from 2001 to 2015. For a given industry, computing the first difference generates a missing observation for 2001. Also, taking the lag of the first difference generates a missing observation for 2002. At most, therefore, I am able to employ 13 observations for a given industry, provided that no other data is missing. This is the case for 6 industries. However, there are some industries for which the R\&D expenditures are missing in 2015. For those industries, I am able to employ 12 observations. This is the case for 13 industries. Lastly, despite the fact that the required data is available for Motor Vehicles, Trailers, and Semi-trailers industry for 15 years (from 2001 to 2015), the value-added information for Ships and Boats, Aircraft and Space Craft, and Transportation Equipment N.E.C. industries are only available for 7 years (from 2008 to 2014). This implies that for these 3 industries, I am only able to employ 5 observations. Altogether, I am able to employ 249 observations $(=6 \times 13+13 \times 12+3 \times 5)$.
} 
IERER, may predict any changes in R\&D activities, which is why I examine the effects of IERER depreciation and appreciation separately.

\subsubsection{Real Exchange Rate Depreciation vs. Appreciation}

Table 5 provides the LSDVC estimations for the parameters in Equation 4, setting apart the effects of increase in price competitiveness, measured by lagged depreciation in IERER, on R\&D expenditures. ${ }^{14}$ As indicated above, the effect of lagged appreciation on $R \& D$ expenditures is captured by the parameter for $\triangle I E R E R_{i, t-1}$, while the effect of lagged depreciation on $\mathrm{R} \& \mathrm{D}$ expenditures is captured by the sum of parameters for $\triangle I E R E R_{i, t-1}$ and $\operatorname{Dep}_{i, t-1} \times \triangle I E R E R_{i, t-1}$. I begin by employing a relatively small vector of control covariates. Then, I add further controls. In all estimations, I include a time trend, a vector of time dummies, and a fixed-effect parameter. The results suggest that lagged appreciation in IERER has no significant effects on contemporaneous R\&D expenditures. Given the estimated parameter for $\triangle I E R E R_{i, t-1}, \mathrm{I}$ do not find any evidence to reject $H_{0}: \alpha_{1}=0$. Similarly, the results suggest that lagged depreciation in IERER has no significant effects. Given the estimated parameters for $\triangle I E R E R_{i, t-1}$ and $\operatorname{Dep}_{i, t-1} \times \Delta I E R E R_{i, t-1}$, I do not have enough evidence to reject $H_{0}: \alpha_{1}+\alpha_{2}=0$. As for the auto-regressive term and the control covariates, a pattern similar to baseline results emerges. There is a significant negative correlation between lagged changes in $R \& D$ expenditures and contemporaneous changes in R\&D expenditures (i.e., the adjustment process). Also, an increase in contemporaneous value-added is correlated with an increase in contemporaneous R\&D expenditures. Plus, an increase in contemporaneous exports is correlated with an increase in $\mathrm{R} \& \mathrm{D}$ expenditures, but an increase in lagged exports leads to a decline in $R \& D$ expenditures.

The results in Table 5 suggest that IERER depreciation or appreciation do not have any important effects on R\&D expenditures when we consider all industries together. This may in part be the result of the heterogeneities that are frequently observed in industry-level responses to common exchange rate

\footnotetext{
${ }^{14}$ The details of the estimation procedure in baseline regression, including the initiating estimation, the accuracy of bias correction, and the number of repetitions for standard error computation, apply to the estimations that are reported in Table 5 and the estimations that follow.
} 
shocks. These heterogeneities are, for example, documented for exports responses. Berman, Martin, and Mayer (2012) show that, depending on industry-level productivity (pp. 462-463) or the concentration of firms with superior performance in a given industry (pp. 473-475), export value of different industries may react differently to changes in relative national prices. These heterogeneities are also documented for R\&D responses. As mentioned in Section 2, Funk (2003) and Kaiser et al. (2017) show that varying exposure to international activities may lead to heterogeneous changes in $R \& D$ activities following changes in relative national prices. Motivated by their findings, I examine industry-level heterogeneities in response to IERER depreciation and appreciation.

\subsubsection{Industry Heterogeneities}

In this section, I report the obtained evidence in support of industry-level heterogeneities. First, I examine whether there are any significant differences between the response of highly export-intensive industries, for which the average export intensity is greater than the median value (i.e., ExpInt ${ }_{i}>0.1892$ ), and industries that are not heavily involved in exporting activities. ${ }^{15}$ Table 6 provides the LSDVC estimations for the parameters in Equation 5. Given the estimation results, I conduct four tests as described in Section 4.4:

1. The effect of lagged appreciation in IERER (i.e., $\operatorname{Dep}_{i, t-1}=0$ ) on industry-level R\&D expenditures for industries that are not heavily engaged in exporting activities (i.e., $\left.I n d_{i}=0\right)$ is captured by the parameter associated with $\triangle I E R E R_{i, t-I}$. As shown in columns $I, I I$, and $I I I$, I cannot reject the null hypothesis that this parameter is equal to zero (i.e., $H_{0}: \alpha_{1}=0$ ).

2. The effect of lagged appreciation (i.e., $D e p_{i, t-1}=0$ ) for export-intensive industries (i.e., $I n d_{i}=1$ ) is captured by the sum of parameters associated with $\triangle I E R E R_{i, t-1}$ and $I n d_{i} \times \Delta I E R E R_{i, t-I}$. I cannot reject the null hypothesis that the sum of these parameters is equal to zero (i.e., $H_{0}: \alpha_{1}+\alpha_{2}=0$ ).

3. The effect of lagged depreciation (i.e., $\operatorname{Dep}_{i, t-1}=1$ ) for industries that are not heavily engaged in exporting activities (i.e., $I n d_{i}=0$ ) is captured by the sum of parameters associated with $\triangle I E R E R_{i, t-1}$

\footnotetext{
${ }^{15}$ Figure 3 plots the distribution of export intensities.
} 
and $D e p_{i, t-1} \times \Delta I E R E R_{i, t-1 .}$. I cannot reject the null hypothesis that the sum of these parameters is equal to zero (i.e., $H_{0}: \alpha_{1}+\alpha_{3}=0$ ).

4. The effect of lagged depreciation (i.e., $D e p_{i, t-1}=1$ ) for export-intensive industries (i.e., $I n d_{i}=1$ ) is captured by the sum of parameters associated with $\triangle I E R E R_{i, t-1}, \operatorname{Ind}_{i} \times \triangle I E R E R_{i, t-1}$, $\operatorname{Dep}_{i, t-1} \times \Delta I E R E R_{i, t-1}$, and $\operatorname{Ind}_{i} \times \operatorname{Dep}_{i, t-1} \times \Delta I E R E R_{i, t-1}$. At $10 \%$ level of significance, I can safely reject the null hypothesis that the sum of these parameters is equal to zero (i.e., $H_{0}: \alpha_{1}+\alpha_{2}+$ $\alpha_{3}+\alpha_{4}=0$ ) when a small vector of control covariates is employed (column I). However, this result does not remain statistically significant when I add more control covariates (columns $I I$ and III).

In short, the results in Table 6 suggest that, regardless of export intensities, a lagged appreciation in IERER has no significant effects on contemporaneous R\&D (tests no. 1 and 2). The effects of a lagged depreciation may depend on export intensities. Among industries that are not heavily export-intensive, a lagged depreciation has no significant effects (test no. 3). However, among export-intensive industries, there are some evidence suggesting that a lagged depreciation may have an adverse effect on contemporaneous R\&D activities (test no. 4). Though the obtained evidence are suggestive, they are not yet conclusive.

Beyond the statistical significance of the effect found in test no. 4 , it is important to examine the economic significance of IERER depreciation on R\&D expenditures among export-intensive industries. ${ }^{16}$ As indicated above, I find statistically significant results only when I employ a relatively small vector of control covariates. Thus, in order to gauge the economic importance of the effect of interest, I employ the results reported in column $I$ of Table 6 . It is important to remember that $\triangle R D_{i, t}$ and $\triangle I E R E R_{i, t-1}$ are both first-differences of log values (Section 4.2) - they approximate annual growth rates. It is also important to remember that, among export-intensive industries, the effect of lagged IERER depreciation on contemporaneous $\mathrm{R} \& \mathrm{D}$ expenditures is captured by the sum of parameters associated with $\triangle I E R E R_{i, t-1}$,

\footnotetext{
${ }^{16} \mathrm{I}$ am grateful to an anonymous referee for reminding me of this matter.
} 
$\operatorname{Ind}_{i} \times \Delta I E R E R_{i, t-1}$, Dep $_{i, t-1} \times \Delta I E R E R_{i, t-1}$, and $\operatorname{Ind}_{i} \times \operatorname{Dep}_{i, t-1} \times \Delta I E R E R_{i, t-1}$ (Section 4.4). Given the results in Table 6 , column $I$, the sum of the above parameters is estimated to be equal to 1.95 , with standard error being equal to 1.15 . The lower limit of a $90 \%$ confidence interval for the above sum is 0.06 . The upper limit is $3.84 .{ }^{17}$ Taking into account the point estimate of 1.95 , the estimation results suggest that a $1 \%$ larger decline in IERER at time $t-1$ (i.e., a larger lagged depreciation) leads to $1.95 \%$ decline in the growth rate of R\&D expenditures among export-intensive industries at time $t$. This is a sizable effect, considering the fact that the mean growth rate of $\mathrm{R} \& \mathrm{D}$ expenditures among export-intensive industries in the sample is $8.81 \%$. (The median is $8.21 \%$ ). That being said, the statistical significance of this effect is sensitive to the choice of control covariates.

Second, I examine whether there are any significant differences between the response of industries that are in the middle of export intensity distribution and industries that are on the tails of export intensity distribution. If the average export intensity of an industry is greater or equal to the value of first quartile and it is less than or equal to the value of third quartile (i.e., $0.1192 \leq$ ExpInt $_{i} \leq 0.4061$ ), then it is considered as an industry with medium levels of export intensity. This includes Pharmaceuticals, Fabricated Metal Product (Except Machinery and Equipment), Transport Equipment N.E.C., Pulp, Paper, and Paper Products, Tobacco Products, Computer, Electronic, and Optical Products, Rubber and Plastic Products, Basic Metals: Iron and Steel, Leather Products and Footwear, Basic Metals: Non-ferrous, Chemicals and Chemical Products (Less Pharmaceuticals), and Machinery and Equipment N.E.C. industries. Table 7 provides the LSDVC estimations for the parameters in Equation 5 using this alternative definition for the time-invariant binary variable, $\operatorname{Ind}_{i}$. Given the estimated parameters, I conduct four tests:

1. The effect of lagged appreciation in IERER (i.e., $D e p_{i, t-I}=0$ ) on industry-level R\&D expenditures for industries with very low or very high levels of exporting activities (i.e., Ind $_{i}=0$ ) is estimated

\footnotetext{
${ }^{17}$ I rely on a $90 \%$ confidence interval estimation because the estimated effect of interest is only significant at $10 \%$ level of significance $(\mathrm{p}$-value $=8.9 \%)$.
} 
by the parameter associated with $\triangle I E R E R_{i, t-1}$. As shown in columns $I, I I$, and $I I I$, I cannot reject the null hypothesis that this parameter is equal to zero (i.e., $H_{0}: \alpha_{1}=0$ ).

2. The effect of lagged appreciation (i.e., $D e p_{i, t-1}=0$ ) for industries with medium levels of export intensity (i.e., $I n d_{i}=1$ ) is estimated by the sum of parameters associated with $\triangle I E R E R_{i, t-1}$ and Ind $d_{i} \times \triangle I E R E R_{i, t-I .}$ I cannot reject the null hypothesis that the sum of these parameters is equal to zero (i.e., $H_{0}: \alpha_{1}+\alpha_{2}=0$ ).

3. The effect of lagged depreciation (i.e., $D e p_{i, t-1}=1$ ) for industries with very low or very high levels of exporting activities (i.e., $I n d_{i}=0$ ) is estimated by the sum of parameters associated with $\triangle I E R E R_{i, t-1}$ and $\operatorname{Dep}_{i, t-1} \times \triangle I E R E R_{i, t-1}$. I cannot reject the null hypothesis that the sum of these parameters is equal to zero (i.e., $H_{0}: \alpha_{1}+\alpha_{3}=0$ ).

4. The effect of lagged depreciation (i.e., $D e p_{i, t-1}=1$ ) for industries with medium levels of export intensity (i.e., $I n d_{i}=1$ ) is estimated by the sum of parameters associated with $\triangle I E R E R_{i, t-1}$, $\operatorname{Ind}_{i} \times \Delta I E R E R_{i, t-1}, \operatorname{Dep}_{i, t-1} \times \Delta I E R E R_{i, t-1}$, and $\operatorname{Ind}_{i} \times \operatorname{Dep}_{i, t-1} \times \Delta I E R E R_{i, t-1}$. At $5 \%$ level of significance, I can safely reject the null hypothesis that the sum of these parameters is equal to zero (i.e., $H_{0}: \alpha_{1}+\alpha_{2}+\alpha_{3}+\alpha_{4}=0$ ). The computed p-values decline slightly as I add further control covariates.

In short, the results in Table 7 suggest that there are no significant effects on $R \& D$ from a lagged appreciation in IERER (tests no. 1 and 2). There are also no significant effects from a lagged depreciation in IERER when we consider the industries on the tails of the export intensity distribution (test no. 3). However, among industries with medium levels of export intensity, there are conclusive evidence (pvalue $<5 \%$ ) suggesting that a lagged depreciation in IERER leads to a decline in contemporaneous $R \& D$ expenditures (test no. 4).

To understand the direction of this effect, it is important to consider two points. First, by definition, $\triangle I E R E R_{i, t-1}$ is less than zero for lagged depreciations (Equations 1 and 2). Second, as reported in Table 7, the sum of parameters associated with $\triangle I E R E R_{i, t-1}, \operatorname{Ind}_{i} \times \triangle I E R E R_{i, t-1}, \operatorname{Dep}_{i, t-1} \times \Delta I E R E R_{i, t-1}$, and 
Ind $_{i} \times$ Dep $_{i, t-1} \times \Delta I E R E R_{i, t-1}$ is statistically greater than zero. Thus, considering lagged depreciation (i.e., $D e p_{i, t-1}=1$ ) among industries with medium export intensity (i.e., $I n d_{i}=1$ ), the estimation results suggest that a decline in $\triangle I E R E R_{i, t-1}$ leads to a decline in $\triangle R D_{i, t .}{ }^{18}$

It is, again, important to examine the economic significance of the results for test no. $4 .{ }^{19}$ Unlike the results for industries with high export intensity, the statistical significance of the effect of IERER depreciation on $R \& D$ expenditures among industries with medium levels of export intensity does not depend on the size of the vector for control covariates. Nevertheless, I first employ the results from the regression with smaller vector of control covariates (Table 7, column $I$ ), so I could compare the obtained results with the previously reported results for industries with high export intensity (Table 6, column $I$ ). As mentioned above, the effect of lagged IERER depreciation on contemporaneous R\&D expenditures among the industries at the middle of export intensity distribution is captured by the sum of parameters associated with $\triangle I E R E R_{i, t-1}, \operatorname{Ind}_{i} \times \Delta I E R E R_{i, t-1}, \operatorname{Dep}_{i, t-1} \times \Delta I E R E R_{i, t-1}$, and $\operatorname{Ind}_{i} \times \operatorname{Dep}_{i, t-1} \times \Delta I E R E R_{i, t-1}$. The sum of the estimated parameters, reported in column $I$ of Table 7, is equal to 2.38. The standard error is equal to 1.20 . The lower limit of a $95 \%$ confidence interval for the above sum is 0.03 . The upper limit is $4.73 .^{20}$ Taking into account the point estimate of 2.38 , the estimation results suggest that a $1 \%$ larger decline in IERER at time $t-1$ (i.e., a larger lagged depreciation) leads to $2.38 \%$ decline in the growth rate of R\&D expenditures among the industries with medium levels of export intensity at time $t$. This is again a sizable effect, considering the fact that the mean growth rate of $R \& D$ expenditures among the industries in the middle of export intensity distribution is $9.81 \%$. (The median is $9.29 \%$ ). ${ }^{21}$ The economic significant of the

\footnotetext{
18 To provide a numerical example for a decline in $\triangle I E R E R_{i, t-1}$, I rely on the distribution of lagged changes in IERER. The mean for the changes is 0.0044 , and the standard deviation is 0.0801 . Thus, one standard deviation move to the left of the mean would already produce a lagged depreciation (-0.0757). Two standard deviations move to the left of the mean would produce a larger lagged depreciation (-0.1558). Histogram and detailed summary statistics are available upon request.

${ }^{19} \mathrm{I}$ am grateful to an anonymous referee for reminding me of this matter.

${ }^{20}$ I rely on a $95 \%$ confidence interval estimation because the estimated effect of interest is only significant at $5 \%$ level of significance $(\mathrm{p}$-value $=4.8 \%)$.

${ }^{21}$ To understand the magnitude of this adverse effect more fully, one may consider the average industry-level real R\&D expenditure among industries with medium levels of export intensity between 2001 and 2015. This average figure amounts to 445 billion Korean wons - it is approximately equal to 396 million US dollars, given the average exchange rate during the same time window. An annual growth rate of $9.81 \%$ leads to an increase of 43.7 billion Korean wons (38.9 million US dollars) in industry-level R\&D expenditures after one year, while an annual growth rate of $7.43 \%(=9.81 \%-2.38 \%)$ leads to an increase of only 33.1 billion Korean wons (29.5 million US dollars) after one year.
} 
above effect increases slightly as we add more control covariates (columns $I I$ and $I I I$ in Table 7): the sum of the estimated parameters of interest increases to 2.44 , with standard error being equal to 1.19 .

As for control covariates, the results in Tables 6 and 7 are quite similar to the baseline findings. There is a significant negative correlation between lagged changes in R\&D expenditures and contemporaneous changes in $R \& D$ expenditures (i.e., the adjustment process). Plus, it is evident that an increase in contemporaneous value-added is correlated with an increase in contemporaneous R\&D expenditures. Further, I find that an increase in contemporaneous exports is correlated with an increase in contemporaneous R\&D expenditures, and that an increase in lagged exports leads to a decline in contemporaneous $\mathrm{R} \& \mathrm{D}$ expenditures. It is also worth noting that for the results that are reported in column III of Table 7, I find that an increase in contemporaneous imports is correlated with an increase in contemporaneous R\&D expenditures. However, the p-value is slightly above the conventional threshold. I also find that an increase in lagged interest rate leads to a decline in contemporaneous R\&D expenditures. The p-value is again slightly above the conventional threshold.

The estimation results reported in Tables 6 and 7 provide some evidence for the existence of heterogenous R\&D responses to changes in relative national prices. In particular, they suggest that IERER depreciation may have an economically significant adverse effect on industry-level R\&D expenditures among industries with medium levels of export intensity. As mentioned in Section 4.4, these industries are more likely to engage in strategic pricing compared to industries with high export intensity, who are likely to offer their products under competitive prices abroad, or industries with low export intensity, who do not have enough incentives to engage in strategic international pricing (e.g., Garetto, 2016). Thus, in response to real exchange rate depreciation, industries at the middle of export intensity distribution are less likely to adjust their international prices, measured in domestic currency. However, the cost of imported inputs increases following exchange rate depreciation. That, in return, leads to a lower profit margin, which has an adverse effect on $R \& D$ expenditures. I discuss this mechanism more fully in Section 4.6. 


\subsubsection{Robustness}

In what follows, I conduct three robustness checks for the results that are reported in Table 7. In the interest of space, I only report the robustness checks for the regression function with the largest vector of control covariates (as shown in column III of Table 7). I obtain similar results when I employ fewer control covariates.

First, I consider a narrower band for those industries with medium export intensities. The average export intensity of an industry with medium levels of export intensity is, in this case, strictly greater than the value of first quartile and strictly less than the value of third quartile (i.e., $0.1192<$ ExpInt $_{i}<0.4061$ ). This modification entails excluding the first and third quartile industries from the group of industries with medium levels of export intensity. ${ }^{22}$ As seen in Table 8 (column $I$ ), the results remain the same. At $10 \%$ level of significance, I can safely reject the null hypothesis that the sum of parameters associated with $\triangle I E R E R_{i, t-1}, \operatorname{Ind}_{i} \times \Delta I E R E R_{i, t-1}, \operatorname{Dep}_{i, t-1} \times \Delta I E R E R_{i, t-1}$, and $\operatorname{Ind}_{i} \times \operatorname{Dep}_{i, t-1} \times \Delta I E R E R_{i, t-1}$ is equal to zero (i.e., $H_{0}: \alpha_{1}+\alpha_{2}+\alpha_{3}+\alpha_{4}=0$ ), supporting the evidence that a lagged depreciation in IERER has an adverse effect on contemporaneous R\&D activities in industries with medium levels of exporting activities.

Second, I exclude the Electrical Equipment industry from the sample, as it has by far the greatest share of manufacturing R\&D expenditures and the largest magnitude of export intensity. To compare the resulting estimations with the results that are reported in Table 7, I first keep the set of industries with medium levels of export intensity the same as before (column II of Table 8). Then, I modify the set according to the new export intensity distribution (column III of Table 8). ${ }^{23}$ The results remain robust in both cases. At 10\% level of significance, I can safely reject the null hypothesis that the sum of parameters associated with $\triangle I E R E R_{i, t-1}, \operatorname{Ind}_{i} \times \Delta I E R E R_{i, t-1}$, Dep $_{i, t-1} \times \Delta I E R E R_{i, t-1}$, and Ind $d_{i} \times D e p_{i, t-1} \times \Delta I E R E R_{i, t-1}$ is equal to zero (i.e., $H_{0}: \alpha_{1}+\alpha_{2}+\alpha_{3}+\alpha_{4}=0$ ). Thus, even after I drop the most R\&D- and export-intensive

\footnotetext{
22 The industry at the first quartile of export intensity distribution is Pharmaceutical Products industry. The industry at the third quartile is Machinery and Equipment N.E.C.

${ }^{23}$ In the absence of Electrical Equipment industry (column III of Table 8), the Machinery and Equipment N.E.C. industry is not considered as an industry with medium levels of export intensity. It is rather considered as an industry with high level of export intensity.
} 
industry from the sample, the adverse effect of a lagged depreciation in IERER on contemporaneous

R\&D expenditures is evident among industries with medium levels of export intensity.

Third, I include a binary variable to control for the global financial crisis of 2007-2009. As shown in the appendix, the IERER measures drop significantly during the global financial crisis. Controlling for crisis years, I make sure that the main findings of this paper are not driven by the general effects of the slowdown in global economy. The new control variable is set equal to one for 2007,2008 , and 2009. It is equal to zero, otherwise. The results remain the same after I include this new control covariate. Table 8 (column $I V$ ) shows that at $5 \%$ level of significance, I can safely reject the null hypothesis that the sum of parameters associated with $\triangle I E R E R_{i, t-1}, \operatorname{Ind}_{i} \times \Delta I E R E R_{i, t-1}, \operatorname{Dep}_{i, t-1} \times \Delta I E R E R_{i, t-1}$, and $\operatorname{Ind}_{i} \times \operatorname{Dep}_{i, t-1} \times \triangle I E R E R_{i, t-1}$ is equal to zero (i.e., $H_{0}: \alpha_{1}+\alpha_{2}+\alpha_{3}+\alpha_{4}=0$ ), suggesting that the reported results in Table 7 are not driven by the crisis. ${ }^{24}$

\subsection{Discussion}

The above results suggest that a lagged depreciation in IERER leads to a decline in contemporaneous industry-level R\&D expenditures for those industries at the middle of the export intensity distribution. The R\&D expenditures of industries that mostly serve the domestic market or those who are heavily involved in exporting activities do not respond significantly to lagged depreciations.

This pattern is the result of two factors. First, industries with varying export intensities may exhibit different pass-through elasticities. Motivated by the findings in Garetto (2016), industries that are highly export-intensive are likely to offer competitive prices abroad, which implies that they are less likely to engage in strategic international pricing. Also, industries that are not heavily engaged in international markets do not have enough room for strategic international pricing. However, compared to

\footnotetext{
${ }^{24}$ I conduct another small robustness check to make sure that the main findings are not contaminated by few irregularities that are observed in the R\&D data. The observed irregularities are likely to be reporting errors. Most of them are, in fact, detectable in the appendix figures. I exclude the observed irregularities from the sample. In particular, I drop the first difference observations in Textiles industry for 2002 and 2003, Wearing Apparel and Fur industry for 2006 and 2007, Wood and Cork (Not Furniture) industry for 2002, Publishing, Printing, and Reproduction of Recorded Media industry for 2002 and 2003, Basic Metals: Iron and Steel industry for 2002 and 2003, and Computer, Electronic, and Optical Products industry for 2002. Then, I re-estimate the parameters of interest. The results remain fully intact. Detailed description of the above irregularities and robustness results are available upon request.
} 
the industries on the tails of the export intensity distribution, those at the middle are more likely to engage in strategic pricing. Estimating exchange rate pass-through for Korean export prices, Kim (2007) offers some empirical evidence that support this proposition. The industry classification used in his study does not perfectly match the classification in this study. There are yet many similarities. In particular, he shows that producers of Chemical Products, Rubber Products, and General Machineries and Equipment follow local currency pricing strategy. He also shows that producers of Basic Metal Products and Leather Products follow a similar pricing behavior with slightly less intensity, and that producers of Fabricated Metal Products, Precision Instruments, and Paper Products follow a similar pricing behavior with less intensity. ${ }^{25}$ Though there are few industries in his study with high or low export intensity that follow local pricing strategy, the majority of industries that follow local pricing strategy belong to the middle of export intensity distribution as plotted in Figure 3. This pattern may suggest that industries with medium levels of export intensity are more likely to engage in in strategic pricing.

Second, the reliance of Korean industries with medium levels of export intensity on imported intermediate inputs is similar to the reliance of other industries that are on the tails of the export intensity distribution. This is illustrated in Figure 4. In this figure, industries are ranked by their export intensity. Wood and Cork Not Furniture has the lowest export intensity, and Electrical Equipment has the highest export intensity. For a given industry, I plot the amount of imported intermediate inputs in 2000, adjusted by the total demand for domestic and imported intermediate inputs. I compute the above measure using the input-output table, available at Bank of Korea's Economic Statistics System (2018). ${ }^{26}$ For example, consider Food Products and Beverages industry. In 2000, the total imported intermediate inputs demand of this industry adds up to 5.23 trillion wons (about 4.6 billion US dollars), and the total domestic

\footnotetext{
${ }^{25}$ Normalizing the benchmark for local currency pricing to 1 , his estimations for the parameters associated with Chemical Products, Rubber Products, and General Machinery and Equipment industries are greater than 0.7 yet less than 0.8. (No single industry has an estimated parameter greater than 0.75.) His estimations for the parameters associated with Basic Metal Products and Leather Products industries are greater than 0.6 yet less than 0.7 . Also, his estimations for the parameters associated with Fabricated Metal Products, Precision Instruments, and Paper Products industries are greater than 0.5 yet less than 0.6.

${ }^{26}$ Unfortunately, the input-output tables are not available for the entire time series of the panel in use (2001-2015). That is why I only use the information in 2000, just one year before the panel begins. Also, given data limitations, I am unable to compute the ratio of imported inputs over total intermediate inputs demand for two industries: Transport Equipment, N.E.C. and Ships and Boats. Thus, I only include 20 industries in Figure 4.
} 
intermediate inputs demand adds up to 21.72 trillion wons (about 19.2 billion US dollars). As a result, the amount of imported intermediate inputs, adjusted by the total intermediate inputs demand is equal to $19.40 \%(=5.23 /(5.23+21.72))$. Using this measure, the median reliance on imported intermediate inputs among the industries at the middle of export intensity distribution is $18.78 \%$, and the median reliance on imported intermediate inputs among the industries on the tails is $15.07 \% .{ }^{27}$ This implies that, despite differences in exporting activities, the dependence on imported intermediate inputs is similar among the two groups of industries that are of interest in this study.

The above factors are quite important when we consider the complementarities between R\&D activities and international sourcing. Bøler et al. (2015) provide some evidence for this complementarity. They show that a decline in relative cost of $R \& D$ activities may increase $R \& D$ expenditures as well as imports of intermediate inputs. Given this complementarity, Chen (2017) argues that an increase in relative cost of intermediate inputs as a result of currency undervaluation may adversely affect $R \& D$ expenditures. Though the dependence on imported inputs are similar among the two groups of industries that are of interest in this study, the pass-through elasticities are different. Industries with medium levels of export intensity are more likely to engage in strategic pricing to keep their prices competitive. For them, an increase in cost of imported intermediate inputs as a result of real depreciation may lead to a decline in R\&D expenditures. In fact, as mentioned in Section 2, Alfaro et al. (2018) show that among firms in Latin America and Eastern Europe, which are less export oriented and rely heavily on imported inputs, a real depreciation may have significant negative effects on $R \& D$ activities.

In short, while their reliance on imported intermediate inputs is similar to other industries, the Korean industries that are at the middle of export intensity distribution are more likely to engage in strategic pricing to keep their prices competitive (i.e., relatively lower pass-through elasticities). Thus, a lagged depreciation in IERER, which could be the result of a lagged depreciation in nominal exchange rate affecting import prices, is more likely to lead to a decline in contemporaneous R\&D expenditures in

\footnotetext{
${ }^{27}$ The mean reliance measures are $23.08 \%$ and $18.44 \%$, respectively.
} 
those industries. For industries on the tails, which are likely to have greater pass-through elasticities, the above effect is insignificant.

\section{Conclusion}

This study examines how changes in industry-level relative national prices affect innovation input in a small open economy. I make use of a panel of industry-level R\&D and industry-specific effective real exchange rate data in Korea for 22 manufacturing industries over 15 years, from 2001-2015. I employ the Corrected Least Square with Dummy Variables estimation technique, which is widely known to perform better than conventional General Method of Moments estimation technique when cross-section and timeseries dimensions are relatively small.

The results show that a lagged depreciation in industry-specific effective real exchange rate leads to a decline in contemporaneous R\&D expenditures in industries with medium levels of export intensity. This effect is insignificant, however, among industries that mostly serve the domestic market and among industries that are heavily engaged in exporting activities. The resulting pattern could be the outcome of differences in pass-through elasticities. While their reliance on imported intermediate inputs is similar to other industries, the Korean industries with medium levels of export intensity are more likely to engage in strategic pricing and have lower pass-through elasticities. As a result, a lagged depreciation in the nominal exchange rate, leading to depreciation in the industry-specific effective real exchange rate and an increase in relative price of imported intermediate inputs, may adversely affect their R\&D expenditures. In other industries, higher pass-through rate may restrain this adverse effect. This finding implies that, despite potential growth-promoting effects (e.g., Hausmann, Pritchett, and Rodrik, 2005; Rodrik, 2008),

real exchange rate depreciation may impede the growth of innovative activities in a small open economy. This adverse effect is, in particular, more likely among industries that engage in strategic pricing.

Further research may provide more insights about how firms in different industries with varying export intensity choose between different types of investments (e.g., investments in capital goods vs. investments in innovative capabilities) when they gain price competitiveness. Also, detailed firm level data may reveal more information about the variations in pricing strategy and reliance on imported inputs, 
which could determine the optimal $R \& D$ responses to changes in relative national prices. Conditional upon their reliance on imported inputs, the findings of this paper suggest that firms that engage more heavily in strategic pricing are more likely to reduce their R\&D expenditures in response to real exchange rate depreciation. This hypothesis could be tested when detailed data are available about prices and imported inputs. Lastly, considering investments in innovative capabilities, more detailed data could help us identify how changes in relative national prices may affect the relative allocation of resources that are used in fundamental research versus resources that are used in development efforts. 


\section{Tables}

Table 1: Summary of previous empirical findings

\begin{tabular}{|c|c|c|c|}
\hline $\begin{array}{l}\text { Author(s) and } \\
\text { publication year }\end{array}$ & Data & $\begin{array}{l}\text { Main estimation } \\
\text { method(s) }\end{array}$ & Main findings \\
\hline $\begin{array}{l}\text { Zietz and Fayissa } \\
\text { (1994) }\end{array}$ & $\begin{array}{l}\text { Panel of } 360 \\
\text { manufacturing } \\
\text { firms from } 1975 \text { to } \\
1987 \text { in the US. }\end{array}$ & $\begin{array}{l}\text { Ordinary Least } \\
\text { Square, Fixed } \\
\text { Effect, and } \\
\text { Random Effect. }\end{array}$ & $\begin{array}{l}\text { Increase in R\&D expenditures in response to exchange rate } \\
\text { appreciation among firms in } R \& D \text {-intensive industries. }\end{array}$ \\
\hline Funk (2003) & $\begin{array}{l}\text { Panel of } 269 \\
\text { manufacturing } \\
\text { firms from } 1979 \text { to } \\
1994 \text { in the US. }\end{array}$ & $\begin{array}{l}\text { Pooled Mean } \\
\text { Group }\end{array}$ & $\begin{array}{l}\text { Increase in R\&D expenditures in response to exchange rate } \\
\text { depreciation among exporting firms. } \\
\text { Also, decline in R\&D expenditures in response to exchange } \\
\text { rate appreciation among purely domestic firms. }\end{array}$ \\
\hline $\begin{array}{l}\text { Becker and Pain } \\
(2008)\end{array}$ & $\begin{array}{l}\text { Panel of } 11 \\
\text { manufacturing } \\
\text { industries from } \\
1993 \text { to } 2000 \text { in } \\
\text { the UK. }\end{array}$ & $\begin{array}{l}\text { Ordinary Least } \\
\text { Square and } \\
\text { Dynamic Panel } \\
\text { Data }\end{array}$ & $\begin{array}{l}\text { Decline in R\&D expenditures in response to exchange rate } \\
\text { depreciation among manufacturing industries. }\end{array}$ \\
\hline Chen (2017) & $\begin{array}{l}\begin{array}{l}\text { Panel of } 49 \\
\text { developed and } \\
\text { developing } \\
\text { countries from } \\
1996 \text { to } 2011 .\end{array} \\
\end{array}$ & $\begin{array}{l}\text { Fixed Effect and } \\
\text { Dynamic Panel } \\
\text { Data }\end{array}$ & $\begin{array}{l}\text { Decline in aggregate } \mathrm{R} \& \mathrm{D} \text { expenditures per capita in } \\
\text { response to exchange rate depreciation among developed } \\
\text { countries. }\end{array}$ \\
\hline $\begin{array}{l}\text { Kaiser et al. } \\
(2017)\end{array}$ & $\begin{array}{l}\text { Panel of about } 700 \\
\text { manufacturing } \\
\text { firms from } 1996 \text { to } \\
2015 \text { in } \\
\text { Switzerland. }\end{array}$ & $\begin{array}{l}\text { Fixed Effect } \\
\text { Poisson } \\
\text { Estimation }\end{array}$ & $\begin{array}{l}\text { Increase in R\&D expenditures in response to exchange rate } \\
\text { appreciation for firms that have access to considerable } \\
\text { financial means and small R\&D-intensive firms that that are } \\
\text { not internationally exposed. } \\
\text { Also, decline in R\&D expenditures in response to exchange } \\
\text { rate appreciation for firms with average net international } \\
\text { exposures, firms with low financial means, and large R\&D- } \\
\text { intensive firms that are internationally exposed. }\end{array}$ \\
\hline $\begin{array}{l}\text { Alfaro et al. } \\
(2018)\end{array}$ & $\begin{array}{l}\text { Panel of about } \\
495,000 \text { firms } \\
\text { from } 2001 \text { to } 2010 \\
\text { in } 76 \text { emerging } \\
\text { economies and } 23 \\
\text { industrialized } \\
\text { countries. }\end{array}$ & Fixed Effect & $\begin{array}{l}\text { Increase in R\&D expenditures in response to exchange rate } \\
\text { depreciation among firms in export-oriented emerging } \\
\text { economies in Asia. } \\
\text { Also, decline in R\&D expenditures in response to exchange } \\
\text { rate depreciation among firms in emerging economies in } \\
\text { Latin America and Eastern Europe. }\end{array}$ \\
\hline
\end{tabular}


Table 2: Matching R\&D and IERER data

\begin{tabular}{|c|c|}
\hline Industry Names in R\&D Dataset ${ }^{a}$ & Matched Industries from ERER Dataset $^{\mathrm{b}}$ \\
\hline Food Products and Beverages & Food, Beverages, and Tobacco \\
\hline Tobacco Products & Food, Beverages, and Tobacco \\
\hline Textiles & Textile, Textile Products, Leather, and Footwear \\
\hline Wearing Apparel and Fur & Textile, Textile Products, Leather, and Footwear \\
\hline Leather Products and Footwear & Textile, Textile Products, Leather, and Footwear \\
\hline Wood and Cork (Not Furniture) & Wood Products (Excl. Furniture) \\
\hline Pulp, Paper and Paper Products & Paper, Paper Products, Printing, and Publishing \\
\hline Publishing, Printing and Reproduction of Recorded Media & Paper, Paper Products, Printing, and Publishing \\
\hline Chemicals and Chemical Products (Less Pharmaceuticals) & Chemicals and Chemical Products \\
\hline Pharmaceuticals & Chemicals and Chemical Products \\
\hline Rubber and Plastic Products & Rubber and Plastic Products \\
\hline Non-metallic Mineral Products & Non-metallic Mineral Products \\
\hline Basic Metals, Iron and Steel & Basic Metals and Fabricated Metal Products \\
\hline Basic Metals, Non-ferrous & Basic Metals and Fabricated Metal Products \\
\hline Fabricated Metal Products, Except Machinery and Equipment & Basic Metals and Fabricated Metal Products \\
\hline Machinery and Equipment, N.E.C. & Machinery and Equipment, N.E.C. \\
\hline Computer, Electronic and Optical Products & Electrical Machinery and Apparatus, N.E.C. \\
\hline Electrical Equipment & Electrical Machinery and Apparatus, N.E.C. \\
\hline Motor Vehicles, Trailers and Semi-Trailers & Transport Equipment \\
\hline Aircraft and Spacecraft & Transport Equipment \\
\hline Ships and Boats & Transport Equipment \\
\hline Transport Equipment, N.E.C. & Transport Equipment \\
\hline \multicolumn{2}{|l|}{$\begin{array}{l}\text { Notes: } \\
\text { a) The R\&D dataset is provided by the OECD (2017a). } \\
\text { b) The ERER dataset is provided by RIETI }(2018) \text {. }\end{array}$} \\
\hline
\end{tabular}

Table 3: Panel unit root test results

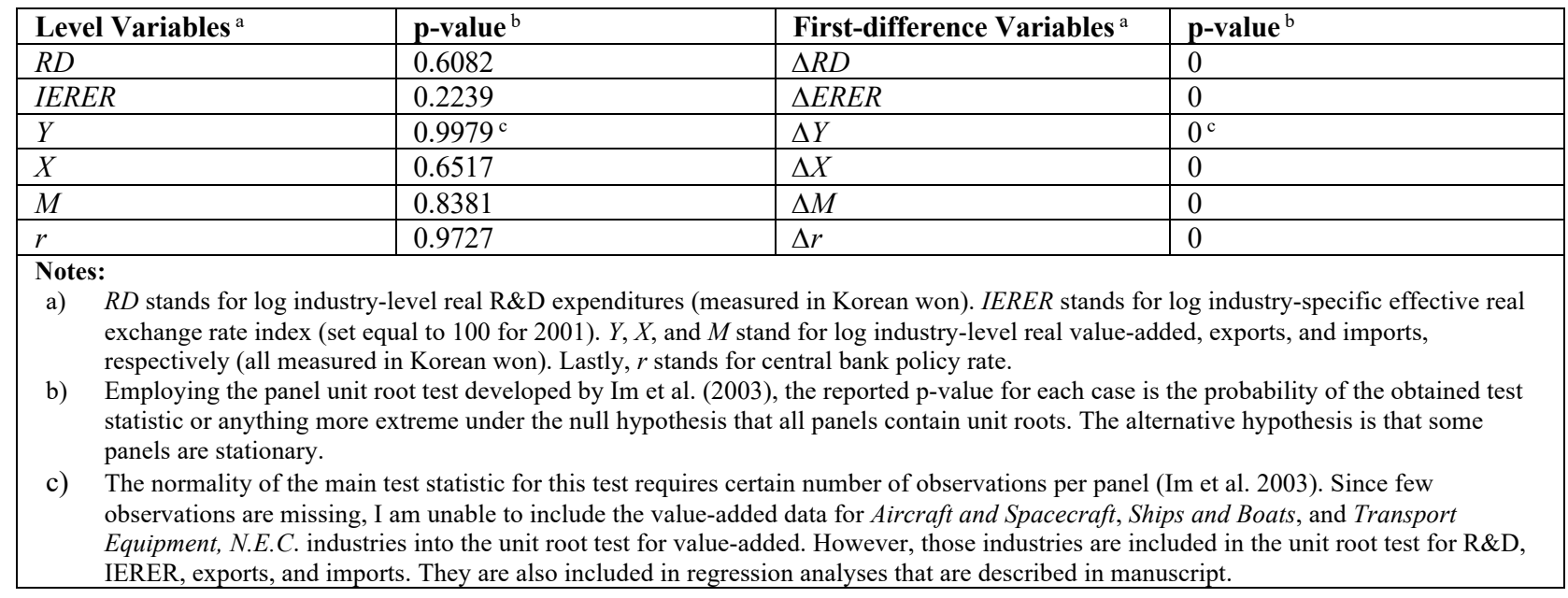


Table 4: Baseline results ${ }^{\text {a }}$

\begin{tabular}{|c|c|c|c|c|}
\hline \multicolumn{2}{|c|}{ LHS Var.: $\Delta \mathrm{RD}_{\mathrm{t}}$} & $I$ & $I I$ & III \\
\hline \multirow{2}{*}{\multicolumn{2}{|c|}{$\Delta \mathrm{RD}_{\mathrm{t}-1}$}} & $-0.309 * * *$ & $-0.315 * * *$ & $-0.288 * * *$ \\
\hline & & $(0.051)$ & $(0.050)$ & $(0.051)$ \\
\hline \multirow{2}{*}{\multicolumn{2}{|c|}{$\Delta$ IERER $_{\mathrm{t}-1}{ }^{\mathrm{b}}$}} & 0.340 & 0.398 & 0.420 \\
\hline & & $(0.621)$ & $(0.625)$ & $(0.625)$ \\
\hline \multirow{2}{*}{\multicolumn{2}{|c|}{$\Delta \mathrm{Y}_{\mathrm{t}}$}} & $0.583 * * *$ & $0.426 * *$ & $0.402 *$ \\
\hline & & $(0.197)$ & $(0.205)$ & $(0.205)$ \\
\hline \multicolumn{2}{|c|}{$\Delta \mathrm{Y}_{\mathrm{t}-1}$} & -0.037 & 0.034 & 0.020 \\
\hline & & $(0.197)$ & $(0.200)$ & $(0.200)$ \\
\hline \multicolumn{2}{|c|}{$\Delta \mathrm{X}_{\mathrm{t}}$} & & $0.266^{* *}$ & $0.259 * *$ \\
\hline & & & $(0.127)$ & $(0.127)$ \\
\hline \multicolumn{2}{|c|}{$\Delta \mathrm{X}_{\mathrm{t}-1}$} & & $-0.234 * *$ & $-0.240 *$ \\
\hline & & & $(0.123)$ & $(0.123)$ \\
\hline \multirow{2}{*}{\multicolumn{2}{|c|}{$\Delta \mathrm{M}_{\mathrm{t}}$}} & & 0.174 & 0.171 \\
\hline & & & $(0.122)$ & $(0.122)$ \\
\hline \multirow{2}{*}{\multicolumn{2}{|c|}{$\Delta \mathrm{M}_{\mathrm{t}-1}$}} & & 0.120 & 0.119 \\
\hline & & & $(0.129)$ & $(0.129)$ \\
\hline \multirow{2}{*}{\multicolumn{2}{|c|}{$\Delta \mathrm{r}_{\mathrm{t}}$}} & & & -0.012 \\
\hline & & & & $(0.051)$ \\
\hline \multirow{2}{*}{\multicolumn{2}{|c|}{$\Delta \mathrm{r}_{\mathrm{t}-1}$}} & & & -0.041 \\
\hline & & & & $(0.066)$ \\
\hline \multicolumn{2}{|c|}{ Time Trend: } & included & included & included \\
\hline \multicolumn{2}{|c|}{ Time Dummies: } & included & included & included \\
\hline \multicolumn{2}{|c|}{ Fixed Effect: } & included & included & included \\
\hline \multicolumn{2}{|c|}{ No. of obs. } & 249 & 249 & 249 \\
\hline \multirow{2}{*}{$\begin{array}{l}\text { The } \\
\text { p-values } \\
\text { for: }\end{array}$} & $\begin{array}{l}\text { AB Test, } \\
\text { AR(1) }{ }^{c}\end{array}$ & 0.026 & 0.023 & 0.023 \\
\hline & $\begin{array}{l}\text { AB Test, } \\
\operatorname{AR}(2)^{c}\end{array}$ & 0.993 & 0.634 & 0.668 \\
\hline
\end{tabular}

Notes:

a) Except for interest rate, all variables are put in log before taking their first difference. Refer to the notes in Table 4 for definition of the variables in use.

b) IERER is industry-specific. It measures industry-level relative national prices. A lagged decline in this measure (i.e., $\triangle I E R E R_{t-1}<0$ ) represents lagged depreciation of industry-specific effective real exchange rate, which implies greater price competitiveness.

c) Arellano-Bond test for no autocorrelation in first difference errors: the underlying assumptions for the initial GMM estimation are met when the null hypothesis is rejected for AR(1) process (i.e., when autocorrelation of order one is evident), while the null hypothesis is not rejected for $\operatorname{AR}(2)$ process (i.e., when the assumption for autocorrelation of order two is not rejected).

Standard errors are reported in parenthesis. $* * *, * * *$ denote significance at the 1 , 5 , and $10 \%$-level, respectively. 
Table 5: Real exchange rate depreciation

\begin{tabular}{|c|c|c|c|c|}
\hline \multicolumn{2}{|c|}{ LHS Var.: $\Delta \mathrm{RD}_{\mathrm{t}}$} & $I$ & II & III \\
\hline \multirow{2}{*}{\multicolumn{2}{|c|}{$\Delta \mathrm{RD}_{\mathrm{t}-1}$}} & $-0.307 * * *$ & $-0.315 * * *$ & $-0.285 * * *$ \\
\hline & & $(0.052)$ & $(0.051)$ & $(0.051)$ \\
\hline \multirow{2}{*}{\multicolumn{2}{|c|}{$\Delta$ IERER $_{\mathrm{t}-1}$}} & -0.047 & 0.222 & 0.255 \\
\hline & & $(0.838)$ & $(0.823)$ & $(0.824)$ \\
\hline \multirow{2}{*}{\multicolumn{2}{|c|}{ Dep $_{\mathrm{t}-1} \times \Delta \mathrm{IERER}_{\mathrm{t}-1}$}} & 1.513 & 1.200 & 1.187 \\
\hline & & $(1.307)$ & $(1.280)$ & $(1.281)$ \\
\hline \multirow{2}{*}{\multicolumn{2}{|c|}{ Dep $_{t-1}$}} & 0.022 & 0.038 & 0.038 \\
\hline & & $(0.059)$ & $(0.058)$ & $(0.058)$ \\
\hline \multicolumn{2}{|c|}{$\Delta \mathrm{Y}_{\mathrm{t}}$} & $0.614 * * *$ & $0.454 * *$ & $0.430 * *$ \\
\hline & & $(0.197)$ & $(0.205)$ & $(0.205)$ \\
\hline \multicolumn{2}{|c|}{$\Delta \mathrm{Y}_{\mathrm{t}-1}$} & -0.013 & 0.058 & 0.043 \\
\hline & & $(0.198)$ & $(0.201)$ & $(0.201)$ \\
\hline \multicolumn{2}{|c|}{$\Delta \mathrm{X}_{\mathrm{t}}$} & & $0.258 * *$ & $0.251 * *$ \\
\hline & & & $(0.127)$ & $(0.127)$ \\
\hline \multicolumn{2}{|c|}{$\Delta \mathrm{X}_{\mathrm{t}-1}$} & & $-0.234 *$ & $-0.241 * *$ \\
\hline & & & $(0.122)$ & $(0.122)$ \\
\hline \multicolumn{2}{|c|}{$\Delta \mathrm{M}_{\mathrm{t}}$} & & 0.182 & 0.178 \\
\hline & & & $(0.122)$ & $(0.122)$ \\
\hline \multirow{2}{*}{\multicolumn{2}{|c|}{$\Delta \mathrm{M}_{\mathrm{t}-1}$}} & & 0.109 & 0.108 \\
\hline & & & $(0.129)$ & $(0.129)$ \\
\hline \multirow{2}{*}{\multicolumn{2}{|c|}{$\Delta \mathrm{r}_{\mathrm{t}}$}} & & & -0.012 \\
\hline & & & & $(0.051)$ \\
\hline \multirow{2}{*}{\multicolumn{2}{|c|}{$\Delta \mathrm{r}_{\mathrm{t}-1}$}} & & & -0.100 \\
\hline & & & & $(0.086)$ \\
\hline \multicolumn{2}{|c|}{ Time Trend: } & included & included & included \\
\hline \multicolumn{2}{|c|}{ Time Dummies: } & included & included & included \\
\hline \multicolumn{2}{|c|}{ Fixed Effect: } & included & included & included \\
\hline \multicolumn{2}{|c|}{ No. of obs. } & 249 & 249 & 249 \\
\hline \multicolumn{2}{|c|}{$\begin{array}{c}\text { p-value for: } \\
H_{0}: \alpha_{1}+\alpha_{2}=0^{\text {a }}\end{array}$} & 0.1886 & 0.2025 & 0.1971 \\
\hline \multirow{2}{*}{$\begin{array}{l}\text { The } \\
\text { p-values } \\
\text { for: }\end{array}$} & $\begin{array}{c}\text { AB Test, } \\
\text { AR(1) }\end{array}$ & 0.024 & 0.023 & 0.023 \\
\hline & $\begin{array}{c}\text { AB Test, } \\
\text { AR(2) }\end{array}$ & 0.987 & 0.714 & 0.748 \\
\hline \multicolumn{5}{|c|}{$\begin{array}{l}\alpha_{1} \text { is the parameter associated with variations in } \triangle I E R E R_{t-1} \text {, and } \alpha_{2} \text { is the } \\
\text { parameter associated with variations in the interaction term, Dep } \\
\text { The sum of these parameters represents the effect of lagged depreciation, while } \\
\alpha_{1} \text { alone represents the effect of lagged appreciation of IERER. } \\
\text { Refer to the notes in Table } 4 \text { for more information. Standard errors are reported in } \\
\text { parenthesis. } * * *, * *, * \text { denote significance at the } 1,5 \text {, and } 10 \% \text {-level, respectively. }\end{array}$} \\
\hline
\end{tabular}


Table 7: Industry heterogeneities ( $I n d_{i}=1$ for industries with medium levels of export intensity)

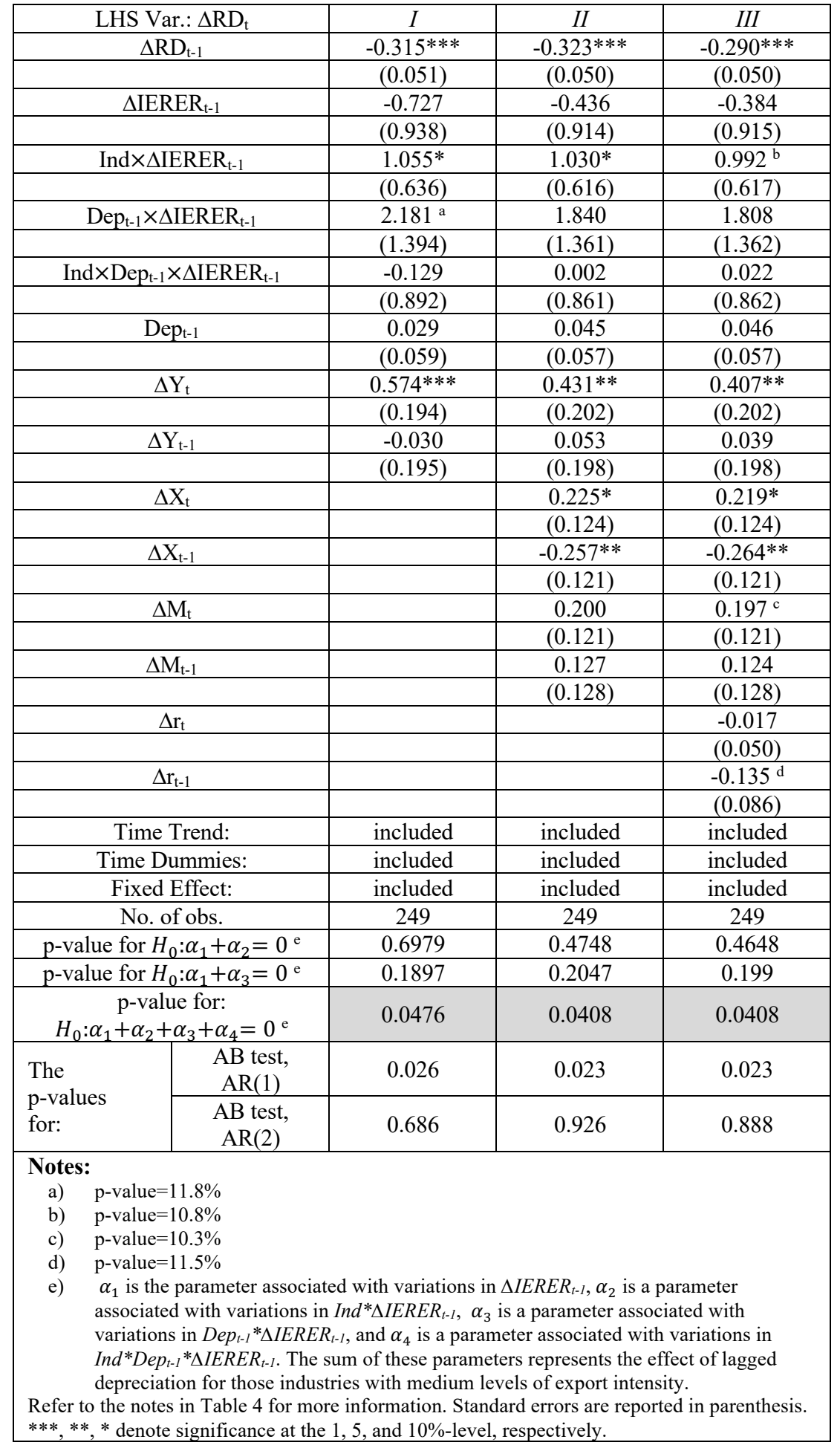


Table 8: Robustness tests

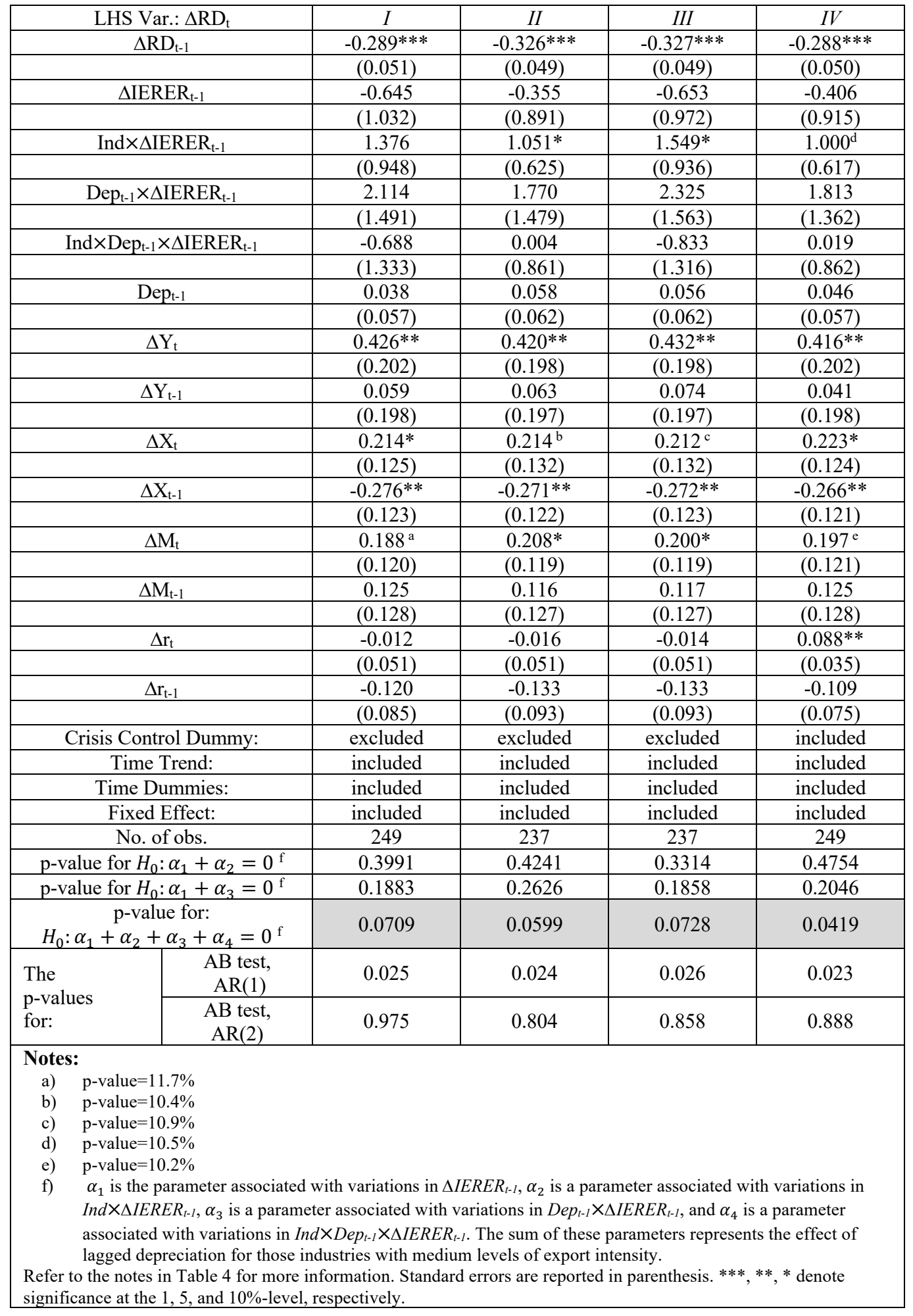




\section{Figures}

Figure 1: Industry-specific shares in aggregate manufacturing R\&D in Korea

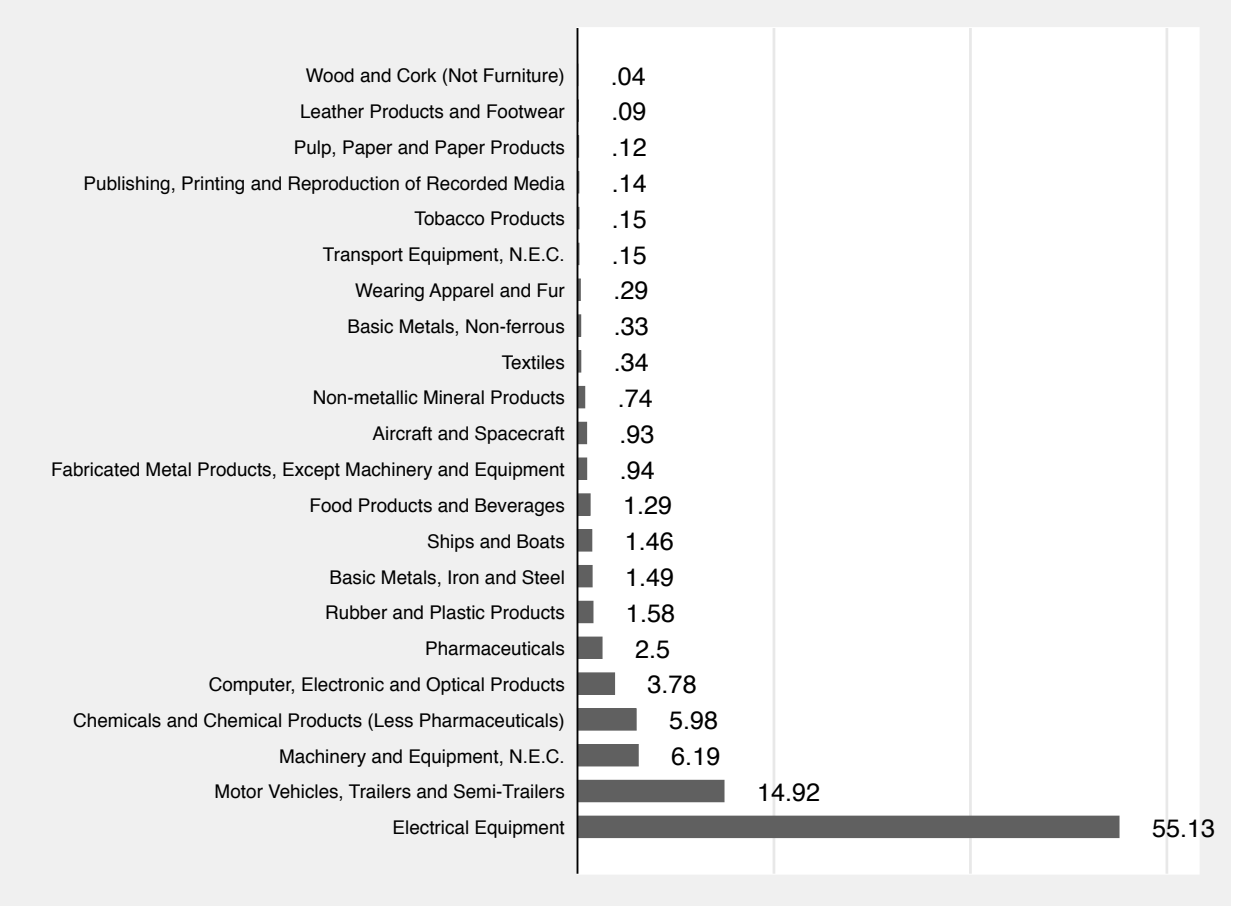

Figure 2: Variations in the IERER measures

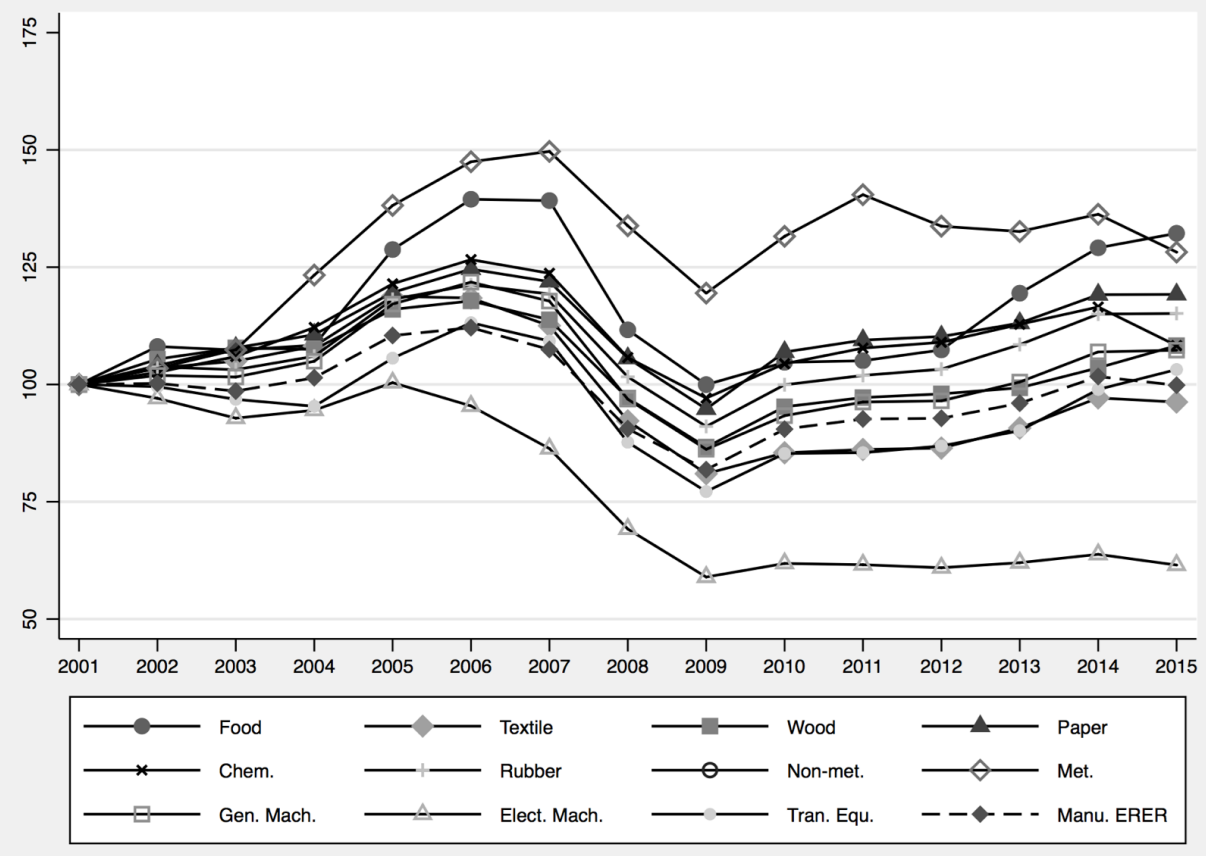


Figure 3: Industry-specific average export intensities

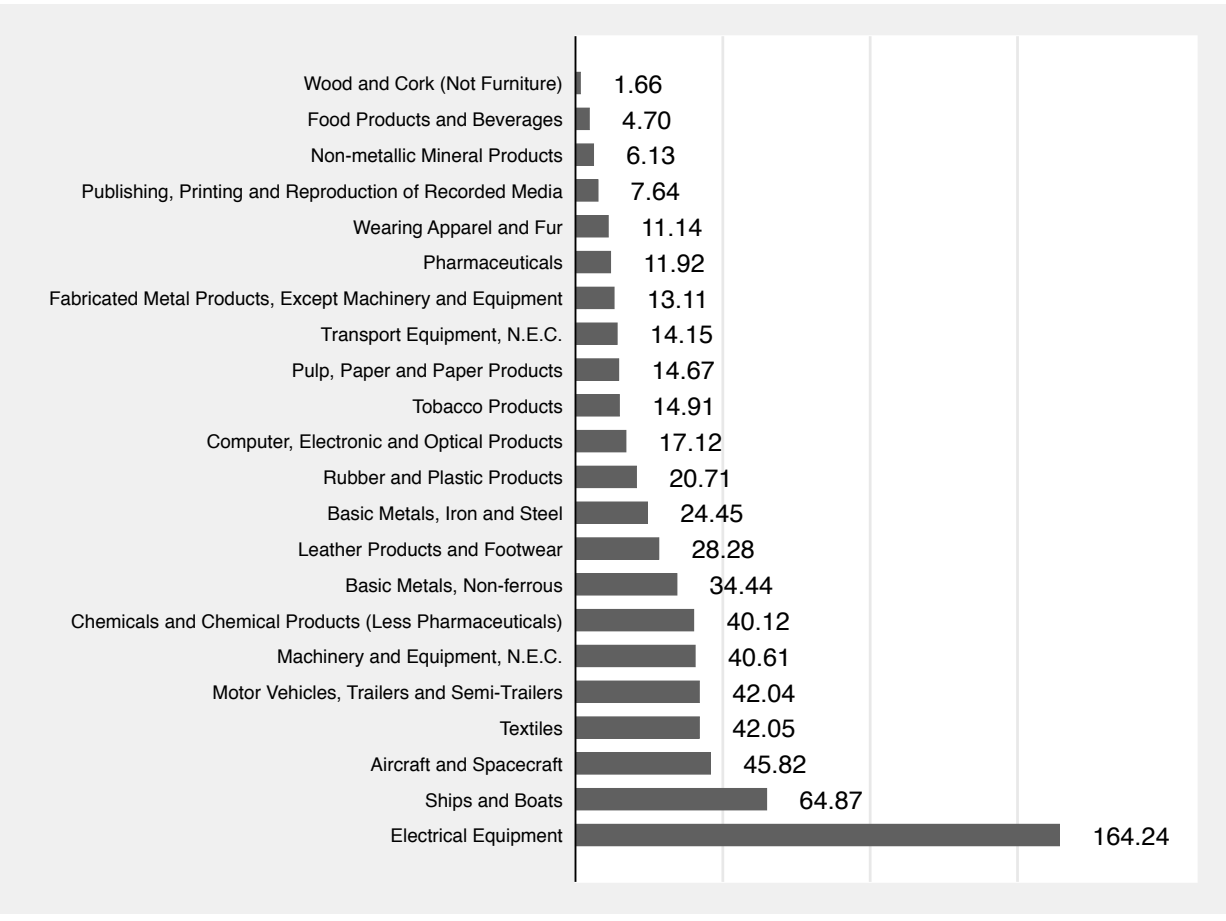

Figure 4: Industry-specific reliance on imported inputs

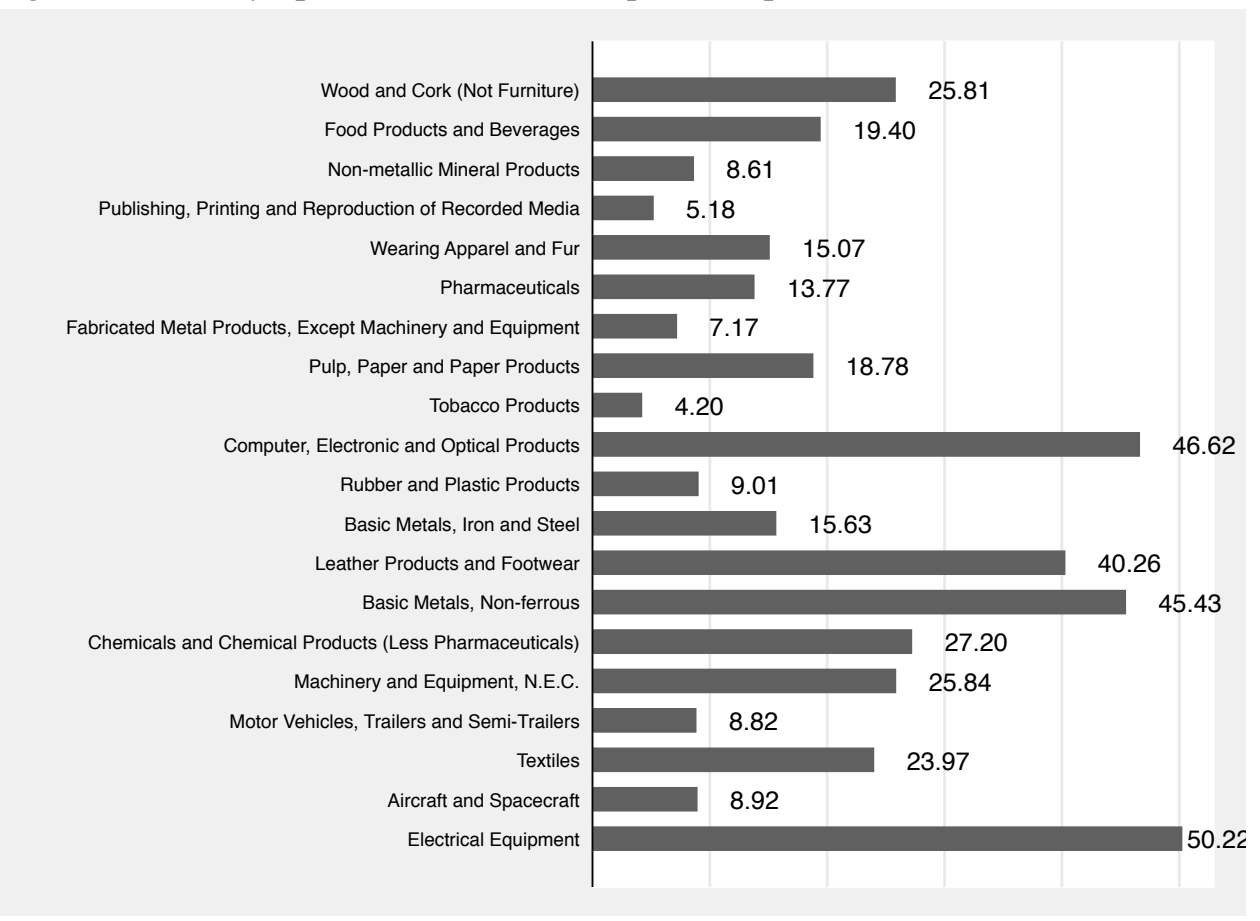




\section{References}

Alfaro, L., Cuñat, A., Fadinger, H., \& Liu, Y. (2018). The real exchange rate, innovation and productivity: Regional heterogeneity, asymmetries and hysteresis (NBER Working Paper No. 24633). Cambridge, MA: The National Bureau of Economic Research

Antonelli, C., Crespi, F., \& Scellato, G. (2012). Inside innovation persistence: New evidence from Italian micro-data. Structural Change and Economic Dynamics, 23(4), 341-353.

Arellano, M., \& Bond, S. (1991). Some tests of specification for panel data: Monte Carlo evidence and an application to employment equations. The Review of Economic Studies, 58(2), 277-297.

Arellano, M., \& Bover, O. (1995). Another look at the instrumental variable estimation of errorcomponents models. Journal of Econometrics, 68(1), 29-51.

Autor, D., Dorn, D., Hanson, G., Pisano, G., \& Shu, P. (2017). Foreign competition and domestic innovation: Evidence from US patents. Retrieved from https://economics.mit.edu/files/11708

Baldwin, J. R., \& Gu, W. (2004). Trade liberalization: Export-market participation, productivity growth, and innovation. Oxford Review of Economic Policy, 20(3), 372-392.

Bank of Korea. (2018). Economic Statistics System. Retrieved from https://ecos.bok.or.kr/EIndex_en.jsp

Becker, B., \& Hall, S. (2009). Foreign direct investment in R\&D and exchange rate uncertainty. Open Economies Review, 20(2), 207-223.

Becker, B., \& Pain, N. (2008). What determines industrial R\&D expenditure in the UK?*. Manchester School, 76(1), 66-87.

Berman, N., Martin, P., \& Mayer, T. (2012). How do different exporters react to exchange rate changes?. The Quarterly Journal of Economics, 127(1), 437-492.

Bloom, N., Draca, M., \& Van Reenen, J. (2016). Trade induced technical change? The impact of Chinese imports on innovation, IT and productivity. The Review of Economic Studies, 83(1), 87-117.

Blundell, R., \& Bond, S. (1998). Initial conditions and moment restrictions in dynamic panel data models. Journal of Econometrics, 87(1), 115-143. 
Bøler, E. A., Moxnes, A., \& Ulltveit-Moe, K. H. (2015). R\&D, international sourcing, and the joint impact on firm performance. American Economic Review, 105(12), 3704-39.

Bruno, G. S. (2005a). Approximating the bias of the LSDV estimator for dynamic unbalanced panel data models. Economics Letters, 87(3), 361-366.

Bruno, G. S. (2005b). Estimation and inference in dynamic unbalanced panel-data models with a small number of individuals. The Stata Journal, 5(4), 473-500

Buddelmeyer, H., Jensen, P. H., Oguzoglu, U., \& Webster, E. (2008). Fixed effects bias in panel data estimators. IZA Discussion Papers: 3487.

Bun, M. J., \& Kiviet, J. F. (2003). On the diminishing returns of higher-order terms in asymptotic expansions of bias. Economics Letters, 79(2), 145-152.

Bustos, P. (2011). Trade liberalization, exports, and technology upgrading: Evidence on the impact of MERCOSUR on Argentinian firms. American Economic Review, 101(1), 304-40.

Chen, S. (2017). Exchange rate undervaluation and R\&D activity. Journal of International Money and Finance, 72, 148-160.

Damijan, J. P., Kostevc, С̆., \& Polanec, S. (2010). From innovation to exporting or vice versa? The World Economy, 33(3), 374-398.

Falk, M. (2006). What drives business Research and Development (R\&D) intensity across Organization for Economic Co-operation and Development (OECD) countries? Applied Economics, 38(5), 533-547.

Funk, M. (2003). The Effects of Trade on Research and Development. Open Economies Review, 14(1), $29-42$.

Garetto, S. (2016). Firms' heterogeneity, incomplete information, and pass-through. Journal of International Economics, 101, 168-179.

Hausmann, R., Pritchett, L., \& Rodrik, D. (2005). Growth accelerations. Journal of Economic Growth, 10(4), 303-329. 
Im, K. S., Pesaran, M. H., \& Shin, Y. (2003). Testing for unit roots in heterogeneous panels. Journal of Econometrics, 115(1), 53-74.

IMF: International Monetary Fund. (2018). International Financial Statistics. Retrieved from http://ata.imf.org/?sk=4C514D48-B6BA-49ED-8AB9-52B0C1A0179B

Ito, K., \& Haneda, S. (2017). Exchange Rate Uncertainty and R\&D Investment: Evidence from Japanese Firms. The Developing Economies, 55(2), 56-74.

Judson, R. A., \& Owen, A. L. (1999). Estimating dynamic panel data models: a guide for macroeconomists. Economics Letters, 65(1), 9-15.

Kaiser, B., Siegenthaler, M., Spescha, A., \& Wörter, M. (2018). The impact of real exchange rates on Swiss firms: Innovation, investment, productivity and business demography. Study on behalf of the State Secretariat for Economic Affairs SECO (No. 109). KOF Studien.

Kim, W. J. (2007). Exchange rate pass-through on disaggregated Korean export prices: a structural VAR approach. The Journal of the Korean Economy, 8(2), 357-376.

Kiviet, J. F. (1995). On bias, inconsistency, and efficiency of various estimators in dynamic panel data models. Journal of Econometrics, 68(1), 53-78.

Lileeva, A., \& Trefler, D. (2010). Improved access to foreign markets raises plant-level productivity... for some plants. The Quarterly Journal of Economics, 125(3), 1051-1099.

Mahagaonkar, P., Schweickert, R., \& Chavali, A. S. (2009). Sectoral R\&D intensity and exchange rate volatility: a panel study for OECD countries (No. 1531). Kiel working paper.

OECD: The Organization for Economic Cooperation and Development. (2017a). OECD's Business Enterprise R\&D Expenditure by Industry. Retrieved from http://stats.oecd.org/Index.aspx?DataSetCode=BERD_INDUSTRY

OECD: The Organization for Economic Cooperation and Development. (2017b). OECD's Science, Technology, and Industry Scoreboard 2017: The digital transformation. Paris: OECD Publishing

OECD: The Organization for Economic Cooperation and Development. (2017c). OECD's STAN Industrial Analysis. Retrieved from http://stats.oecd.org/Index.aspx?DataSetCode=STANI4_2016 
OECD: The Organization for Economic Cooperation and Development. (2019). Gross Domestic Spending on R\&D (Total and \% of GDP). Retrieved from https://data.oecd.org/rd/grossdomestic-spending-on-r-d.htm

Raymond, W., Mohnen, P., Palm, F., \& Van Der Loeff, S. S. (2010). Persistence of innovation in Dutch manufacturing: Is it spurious? The Review of Economics and Statistics, 92(3), 495-504.

RIETI: Research Institute of Economy, Trade, and Industry. (2018). Industry-Specific Nominal and Real Effective Exchange Rates of 25 Countries Worldwide. Retrieved from https://www.rieti.go.jp/users/eeri/en

Rodrik, D. (2008). The real exchange rate and economic growth. Brookings Papers on Economic Activity, 2008(2), 365-412.

Roodman, D. (2009). How to do xtabond2: An introduction to difference and system GMM in Stata. Stata Journal, 9, 1, 86-136.

Sato, K., Shimizu, J., Shrestha, N., \& Zhang, S. (2015). Industry-specific real effective exchange rates in Asia. RIETI Discussion Paper Series: 15-E-036.

Scherer, F. M., \& Huh, K. (1992). R \& D reactions to high-technology import competition. The Review of Economics and Statistics, 202-212.

Teshima, K. (2008). Import Competition and Innovation at the plant level: evidence from Mexico. Unpublished paper, Columbia University.

WITS: World Integrated Trade Solution. (2018). UN Comtrade. Retrieved from http://wits.worldbank.org Woerter, M. (2014). Competition and Persistence of R\&D. Economics of Innovation and New Technology, 23(5-6), 469-489.

WTO: World Trade Organization. (2019). WTO Trade Profiles. Retrieved from http://stat.wto.org/CountryProfile/WSDBCountryPFHome.aspx

Zietz, J., \& Fayissa, B. (1994). The impact of exchange rate changes on investment in research and development. The Quarterly Review of Economics and Finance, 34(2), 195-211. 


\section{Appendix}

Table A.1: Industry codes and names

\begin{tabular}{|c|c|c|}
\hline \multicolumn{2}{|c|}{ ISIC Rev. 3 Code } & Industry Name \\
\hline \multicolumn{2}{|c|}{15} & Food Products and Beverages \\
\hline \multicolumn{2}{|l|}{16} & Tobacco Products \\
\hline \multicolumn{2}{|l|}{17} & Textiles \\
\hline \multicolumn{2}{|l|}{18} & Wearing Apparel and Fur \\
\hline \multicolumn{2}{|l|}{19} & Leather Products and Footwear \\
\hline \multicolumn{2}{|l|}{20} & Wood and Cork (Not Furniture) \\
\hline \multicolumn{2}{|l|}{21} & Pulp, Paper, and Paper Products \\
\hline \multicolumn{2}{|l|}{22} & Publishing, Printing, and Reproduction of Recorded Media \\
\hline \multicolumn{2}{|l|}{$24^{\mathrm{a}}$} & Chemicals and Chemical Products (Less Pharmaceuticals) \\
\hline \multicolumn{2}{|l|}{$24^{\mathrm{a}}$} & Pharmaceuticals \\
\hline \multicolumn{2}{|l|}{25} & Rubber and Plastic Products \\
\hline \multicolumn{2}{|l|}{26} & Non-metallic Mineral Products \\
\hline \multicolumn{2}{|l|}{$27^{\mathrm{b}}$} & Basic Metals, Iron and Steel \\
\hline \multicolumn{2}{|l|}{$27^{\mathrm{b}}$} & Basic Metals, Non-ferrous \\
\hline \multicolumn{2}{|l|}{28} & Fabricated Metal Products, Except Machinery and Equipment \\
\hline \multicolumn{2}{|l|}{29} & Machinery and Equipment, N.E.C. \\
\hline \multicolumn{2}{|c|}{$30-33^{\mathrm{c}}$} & Computer, Electronic, and Optical Products \\
\hline \multicolumn{2}{|c|}{$31-32^{\mathrm{d}}$} & Electrical Equipment \\
\hline \multicolumn{2}{|l|}{34} & Motor Vehicles, Trailers, and Semi-Trailers \\
\hline \multicolumn{2}{|l|}{$35^{\mathrm{e}}$} & Aircraft and Spacecraft \\
\hline \multicolumn{2}{|l|}{$35^{\mathrm{e}}$} & Ships and Boats \\
\hline \multicolumn{2}{|l|}{$35^{\mathrm{e}}$} & Transport Equipment, N.E.C. \\
\hline \multicolumn{3}{|c|}{ Notes: } \\
\hline a) & \multicolumn{2}{|c|}{ The OECD (2017a) breaks down the R\&D data for ISIC Rev. 324 Chemicals and Chemical Products into two sub-categories: 1.) } \\
\hline b) & \multicolumn{2}{|c|}{$\begin{array}{l}\text { The OECD (2017a) breaks down the R\&D data for ISIC Rev. } 327 \text { Basic Metals into two sub-categories: 1.) Basic Metals, Iron and } \\
\text { Steel and 2.) Basic Metals, Non-ferrous. }\end{array}$} \\
\hline c) & \multicolumn{2}{|c|}{$\begin{array}{l}\text { The OECD (2017c), which makes use of ISIC Rev. } 4 \text { codes, provides value-added information only for Computer, Electronics, and } \\
\text { Optical Products industry. To be able to make use of value-added data, I add the R\&D data for ISIC Rev. } 330 \text { Office, Accounting, and } \\
\text { Computing Machinery and ISIC Rev. } 333 \text { Medical, Precision and Optical Instruments, and Watches and Clocks (Instruments) in order } \\
\text { to measure the R\&D activities in Computer, Electronic, and Optical Products industry. }\end{array}$} \\
\hline d) & \multicolumn{2}{|c|}{$\begin{array}{l}\text { The OECD (2017c) provides value-added information only for Electrical Equipment industry. To be able to make use of value-added } \\
\text { data, I add the R\&D data for ISIC Rev. } 331 \text { Electrical Machinery and Apparatus N.E.C. and ISIC Rev. } 332 \text { Radio, TV, and } \\
\text { Communications Equipment and Apparatus in order to measure the R\&D activities in Electrical Equipment industry. }\end{array}$} \\
\hline e) & $\begin{array}{l}\text { The OECD }(20 \\
\text { Aircraft and Sp }\end{array}$ & $\begin{array}{l}\text { a) breaks down the R\&D data for ISIC Rev. } 335 \text { Other Transport Equipment into multiple categories, including } \\
\text { cecraft, Ships and Boats, and Transport Equipment, N.E.C. }\end{array}$ \\
\hline
\end{tabular}


Figure A.1: Time series for the variations in real R\&D and IERER, by industry

Food Products and Beverages

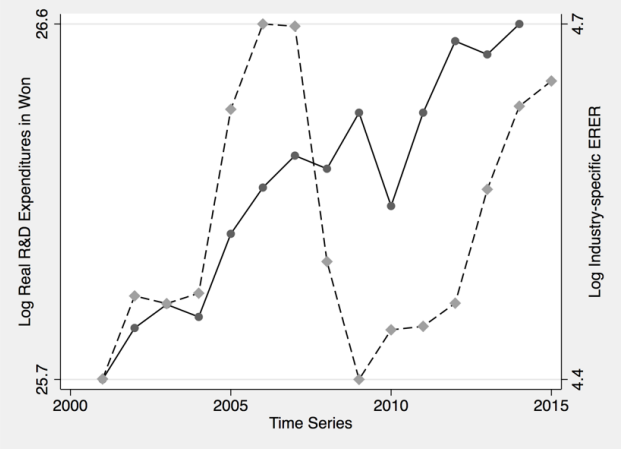

Textiles

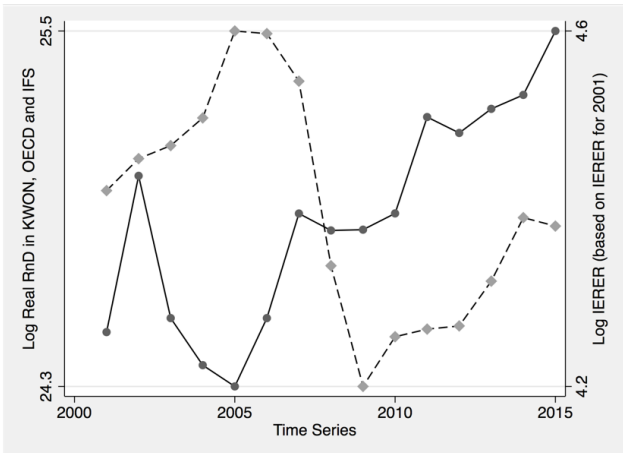

Leather Products and Footwear

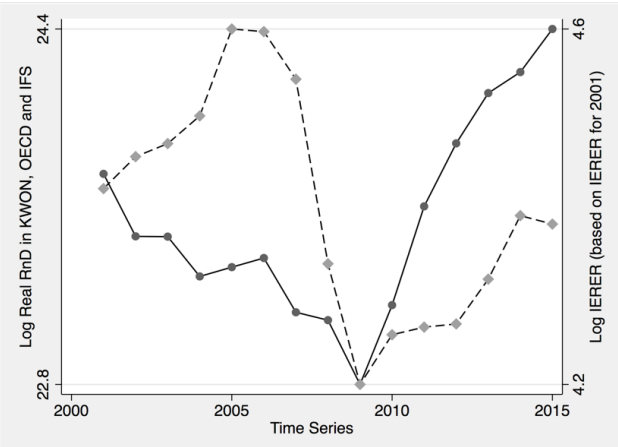

Pulp, Paper and Paper Products

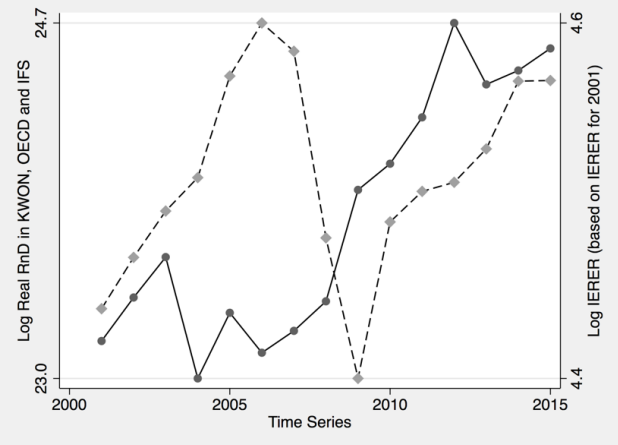

Tobacco Products

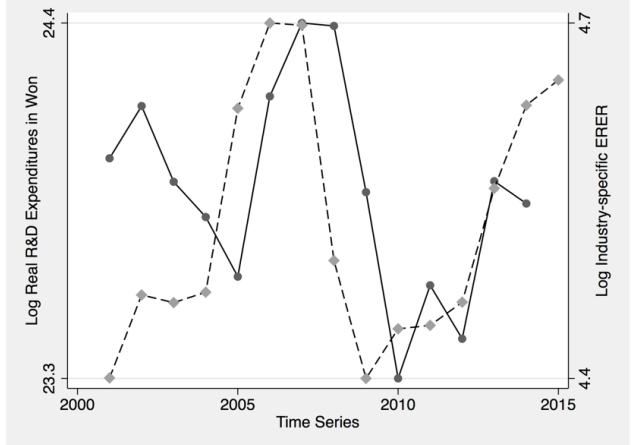

Wearing Apparel and Fur

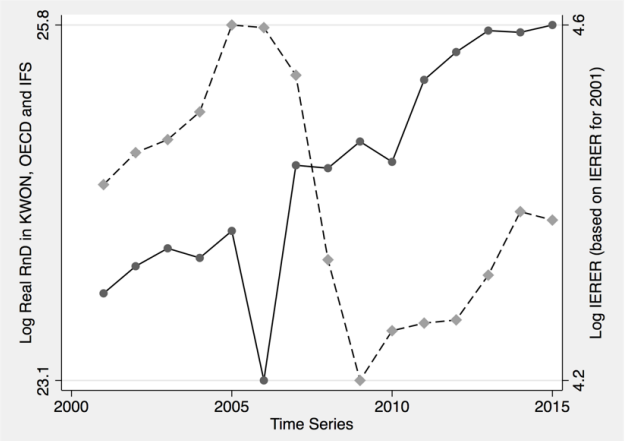

Wood and Cork (Not Furniture)

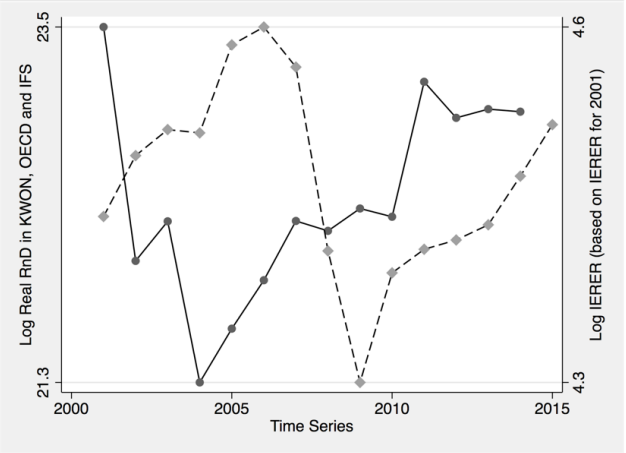

Publishing, Printing and Reproduction of Recorded Media

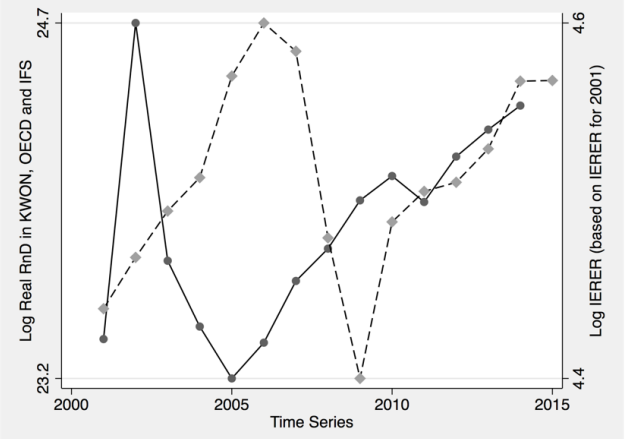

Note: Solid lines show the variations in $R \& D$, and dashed lines show the variations in IERER. 
Figure A.1 (cont'd)

Chemicals and Chemical Products (Less Pharmaceuticals)

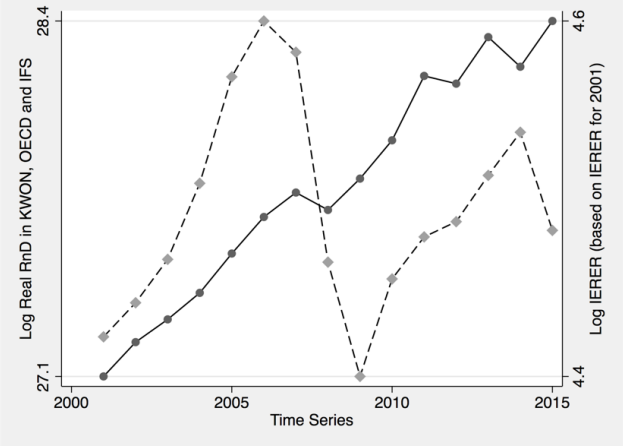

Rubber and Plastic Products

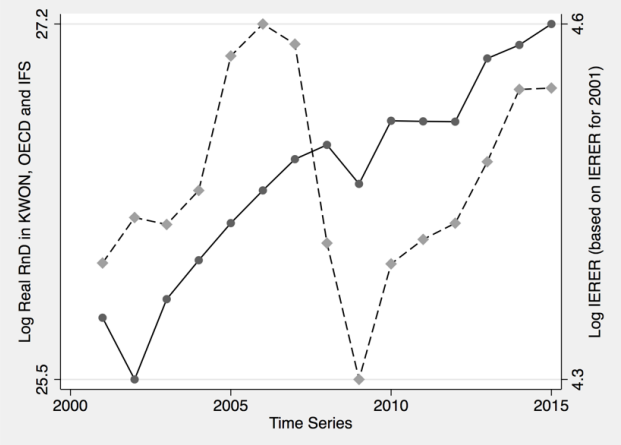

Basic Metals, Iron and Steel

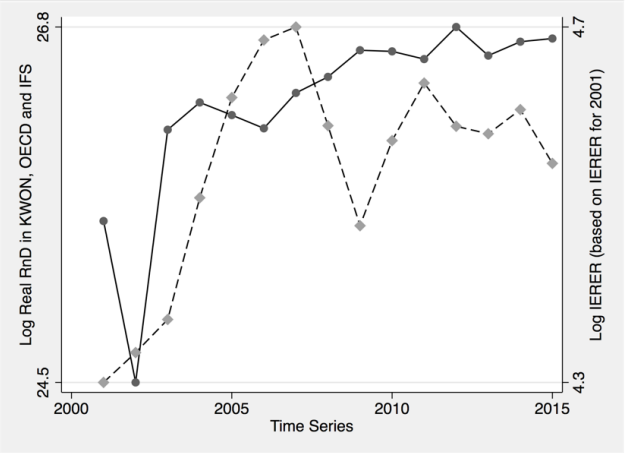

Fabricated Metal Products, Except Machinery and Equipment

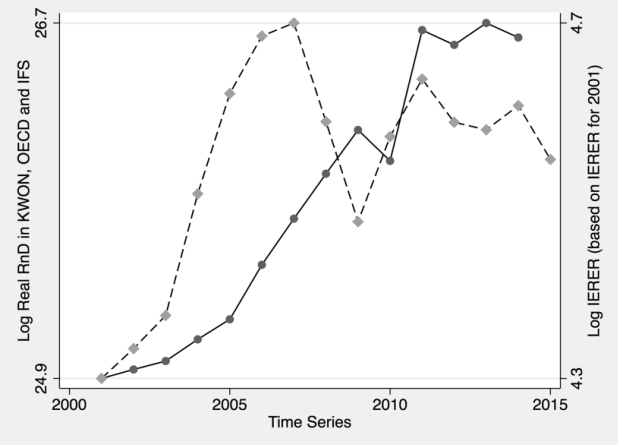

Pharmaceuticals

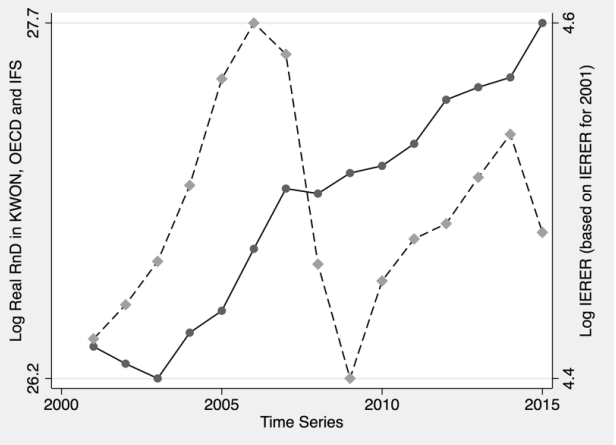

Non-metallic Mineral Products

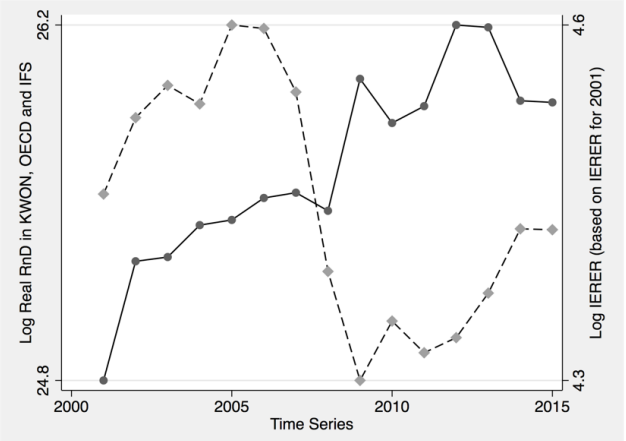

Basic Metals, Non-ferrous

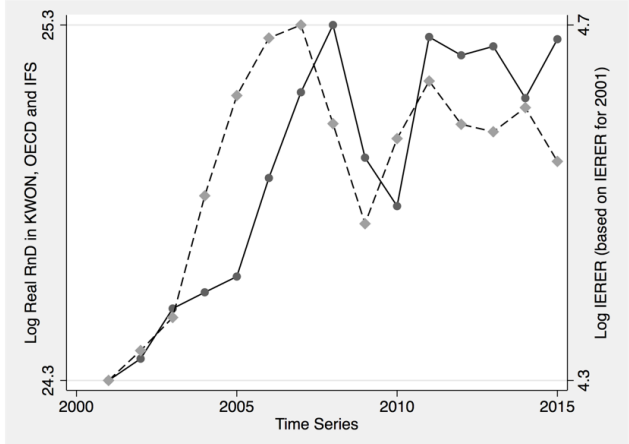

Machinery and Equipment, N.E.C.

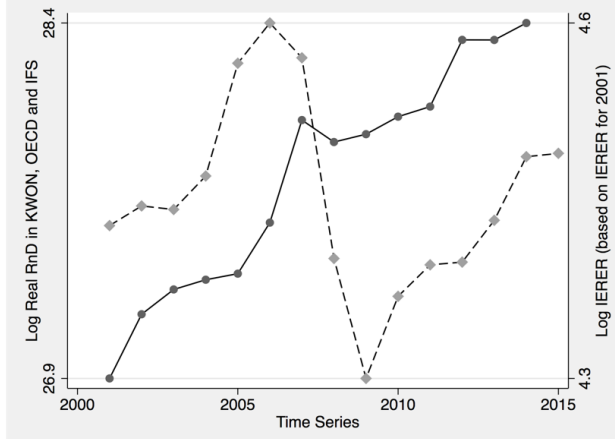

Note: Solid lines show the variations in $R \& D$, and dashed lines show the variations in IERER. 
Figure A.1 (cont'd)

Computer, Electronic and Optical Products

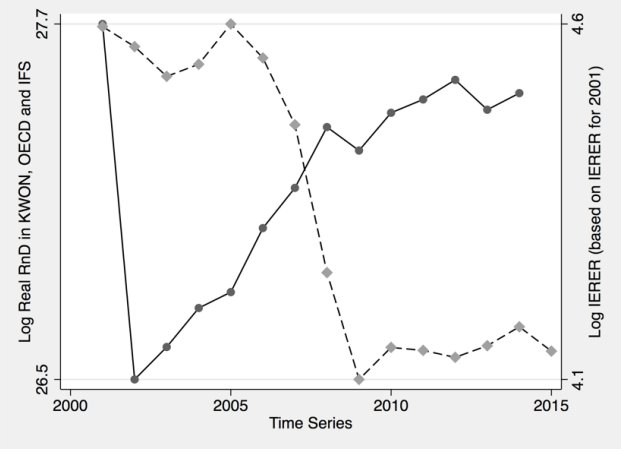

Motor Vehicles, Trailers and Semi-Trailers

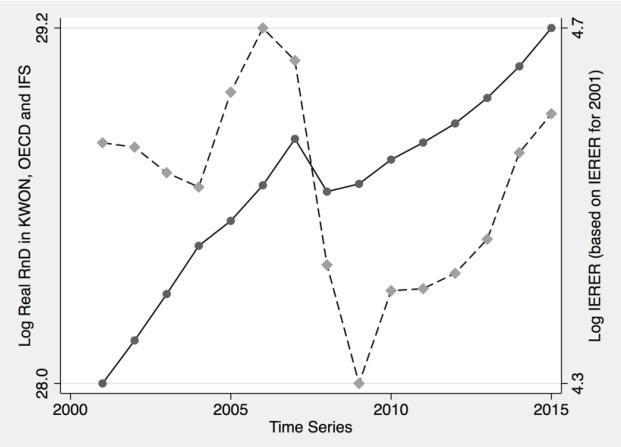

Ships and Boats

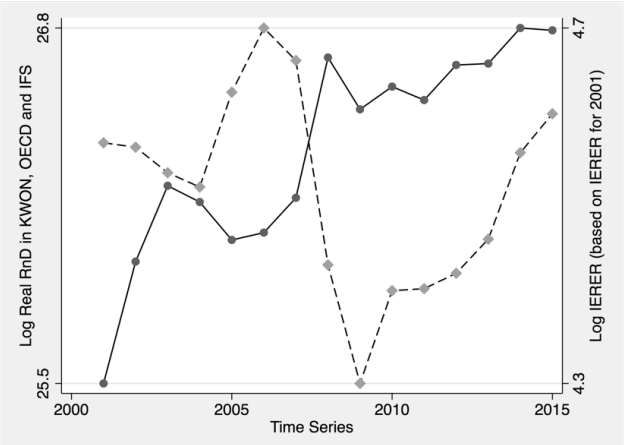

Electrical Equipment

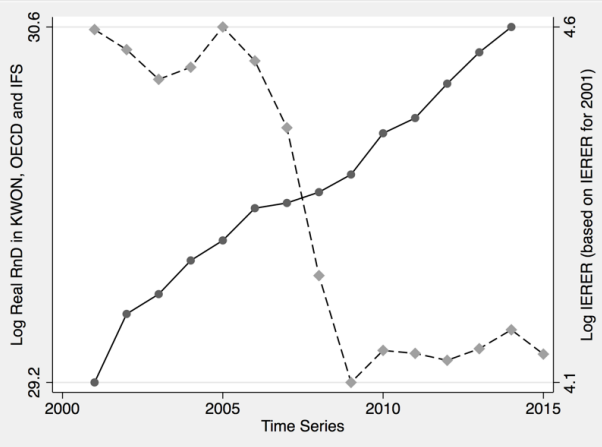

Aircraft and Spacecraft

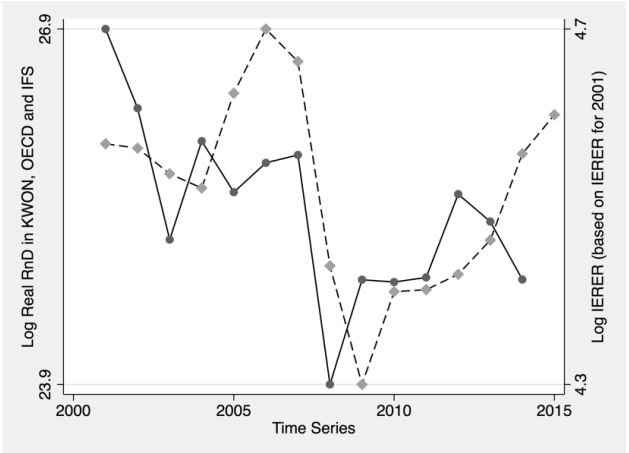

Transport Equipment, N.E.C.

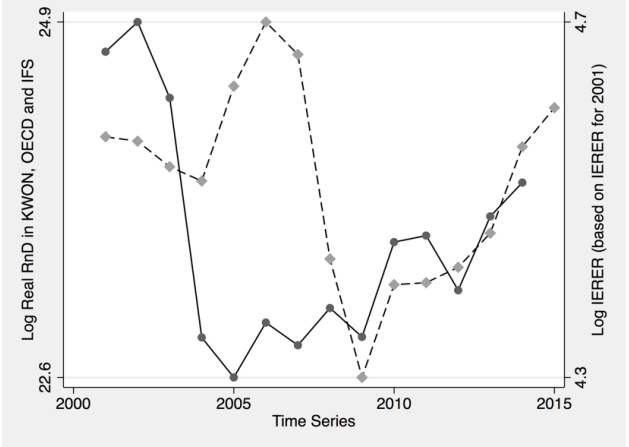

Note: Solid lines show the variations in $R \& D$, and dashed lines show the variations in IERER. 